\title{
TIPOLOGÍA Y GÉNESIS DE LOS CANCIONEROS. LOS CANCIONEROS DE AUTOR 1
}

\author{
VICENÇ BELTRÁN \\ Universitat de Barcelona
}

En el estudio de la lírica medieval juegan un papel cada día más relevante las investigaciones en torno a las fuentes manuscritas que, por su propia naturaleza de objetos arqueológicos, contienen información valiosísima, a veces inalcanzable a través de los métodos de trabajo habituales de la Filología; y entre ellos, los cancioneros, por la complejidad de su construcción y por la variedad habitual de su contenido se han venido revelando como especialmente fértiles en enseñanzas.

En este contexto destacan fuertemente los cancioneros individuales $y$, muy en particular, los cancioneros de autor, elaborados por los propios poetas con criterios que casi siempre superan la mera yuxtaposición de las obras y que son en cada caso atribuibles a su intervención directa. El interés por el cancionero de Francesco Petrarca, caso ciertamente único en la

\footnotetext{
${ }^{1}$ Esta investigación se integra en el seno del proyecto PB93-758 del Programa Sectorial de Promoción General del Conocimiento de la Dirección General de Enseñanza Superior cuyo objeto es el estudio de las técnicas de composición de los cancioneros medievales. El primer trabajo de esta serie, «El caso de Jorge Manrique», fue publicado en Historias y ficciones. Coloquio sobre la literatura del siglo XV, ed. R. Beltrán, J. L. Canet y J. L. Sirera, Valencia, Universidad-Departamento de Literatura Española, 1992, págs. 167-188, el segundo, «La organización de los materiales» fue leído en el coloquio Poetry at Court in Trastámaran Spain, organizado por los profesores M. Gerli y J. Weiss en la Georgetown University, 12-13 de febrero de 1993, y será publicado con las actas del mismo. La tercera entrega, «Dos Liederblätter probablemente autógrafos de Juan del Encina y una posible atribución», puede verse en la Revista de Literatura Medieval, 7, 1995, págs. 41-71, la cuarta, «Las grandes compilaciones y los sistemas de clasificación», en Cultura Neolatina, 55, 1995, págs. 233-265, la quinta, «Dreg de natura de Matfre Ermengaut y el cancionero de Charles de Orléans» ha salido en Romania, 115, 1997, págs. 193-206 y la sexta, "Juan Fernández de Híjar y los cancioneros por adición», en Romance Philology, 50, 1996, págs. 1-19. De uno de los más importantes cancioneros de autor del cuatrocientos, el de Juan del Encina, me he ocupado también en un trabajo de este título, ponencia leída en el Congreso Internacional «Humanismo y Literatura en tiempos de Juan del Encina», que va a ser publicada entre las actas del mismo.
} 
tradición del Medioevo y cuya estrategia compositiva conocemos cada día mejor, ha reavivado en las últimas décadas estos trabajos y ha propiciado no pocos avances que ilustran progresivamente la transmisión escrita de la lírica romance.

Poco se ha hecho en España en este campo ${ }^{2}$, y este poco ha quedado casi reducido al más importante de nuestros cancioneros de autor, el de Íñigo López de Mendoza, marqués de Santillana ${ }^{3}$; y sin embargo, la existencia de varios manuscritos cuatrocentistas, a menudo directamente vinculados al autor, probablemente autógrafos o copias autorizadas por él mismo, invita a abordar su estudio aunque sea sólo con la intención de abrir una nueva línea de investigación en este mundo apasionante que afecta tanto a la historia del libro como a la transmisión de los textos poéticos.

En efecto, la organización de un cancionero personal es algo complejo, donde la intencionalidad del autor y otros condicionantes de tipo externo deben ser armonizados a fin de obtener un conjunto estructurado y significativo. Y el primer condicionante es, como resulta lógico, la cronología misma de los poemas. Hemos de suponer que cada autor tendría un cuaderno o un libro ${ }^{4}$ donde iría copiando sus obras a medida que adquirieran

\footnotetext{
${ }^{2}$ Como precedente de lo que hubiera podido hacerse, véase B. Tittmann, «A Contribution to Study of the Cancionero de Baena Manuscript», en Aquilea, 1. 1968, págs. 190-205 y A. Blecua, «Perdióse un quaderno... Sobre los cancioneros de Baena», en Anuario de Estudios Medievales, 9, 1974-1979, págs. 229-266. A pesar de su interés y sus aspectos innovadores, apenas han tenido continuadores.

${ }^{3}$ Véase en especial el peritaje codicológico de P. M. Cátedra sobre el Cancionero del marqués de Santillana [B. U. S., ms. 2655], Salamanca, Universidad de Salamanca-Iberduero, 1990, vol. II, págs. xxi-xxxi y 1-6, y el trabajo más reciente de Juan C. López Nieto, «Sobre la ordenación de SA8 [Ms. 2655 de la Biblioteca Universitaria de Salamanca] y la secuencia temporal de algunas obras del Marqués de Santillana» Anuario Medieval, 1992, 3 , págs. 158-178. Naturalmente no incluyo en este aspecto los estudios que se han ocupado de los cancioneros como portadores de una obra poética pues, a pesar de su indudable importancia para los estudiosos de la poesía del siglo $\mathrm{xV}$ y de su calidad en general, se orientan en una perspectiva distinta de la que aquí nos ocupa, que sólo suelen tocar marginalmente.

${ }^{4}$ Es notorio que el período trovadoresco conoció los rótulos, de los que conservamos varios testimonios y algún ejemplar completo pero, por su escasa entidad material resulta obvio que debieron tener «un'esistenza delle piú precarie» (D. S. Avalle-L. Leonardi, Manoscritti della letteratura in lingua d'oc, Torino, Einaudi, 1993, págs. 61 y 62). En otro lugar pude identificar dos Liederblätter, pliegos poéticos en obsequio de un protector, salidos de la mano del propio Juan del Encina, y herederos, por tanto, de aquella tradición (véase la nota 1) pero es obvio que éste no era el sistema adecuado para una conservación a largo plazo del texto poético; mis investigaciones en este campo han dejado patente que los colectores de cancioneros (y un cancionero de autor también lo es, máxime cuando opera sobre obras tan amplias como los que ahora nos ocupan) operaban sobre volúmenes prediseñados $\mathrm{y}$, a menudo, encuadernados ya antes de su copia («Las grandes compilaciones y los sistemas de clasificación», especialmente págs. 254-265). Y éste debía ser el continente adecuado para que un poeta pudiera recoger durante años su producción sin peligro de deterioro ni de extravío.
} 
su forma definitiva; y, salvo omisiones o inversiones accidentales en textos de cronología muy próxima, éstas irían quedando en el mismo orden en que fueron compuestas. Salvo intervenciones intencionales a posteriori, que tendrían lugar en el momento de obtener copias o versiones más elaboradas y durante las que cabría plantearse fines específicos (es el caso del Canzoniere petrarquesco) ${ }^{5}$, éste sería el orden habitual del que partiría la transmisión textual.

En el ámbito peninsular un número considerable de testimonios conservados avalan un procedimiento que remonta, como tantas otras cosas, al período trovadoresco. D. S. Avalle demostró hace años la existencia de una pequeña colección de composiciones de Peire Vidal ordenadas cronológicamente, cuya posibilidad de datación correcta habría escapado a cualquier coleccionista medieval que no fuera el propio autor ${ }^{6}$; asimismo, la colección de las canciones de Guiraut Riquier, conservada en dos manuscritos cuyas rúbricas contienen valiosísimas precisiones sobre el año, el mes, el día y hasta la hora en que fueron compuestas y el tiempo que le ocuparon, según una de estas fuentes, fueron copiadas del propio cancionero del autor, y están también por riguroso orden cronológico ${ }^{7}$. Lo mismo sucede con los sonetos recogidos en el cancionero personal de Nicolò de' Rossi, con-

\footnotetext{
${ }^{5}$ Para las fases, la cronología y la complejidad del proceso que llevó a Petrarca a convertir el conjunto de su producción poética vulgar en el prototipo de un cancionero, véase E. H. Wilkins, "The Making of the Canzoniere», en The Making of the Canzoniere and other Petrarchan Studies, Roma, Edizioni di Storia e Letteratura, 1951, cap. IX, revisado en «La formazione del Canzoniere», en Vita del Petrarca e la formazione del "Canzoniere», Milano, Feltrinelli, 1985, págs. 335-384.

${ }^{6}$ Véase su edición de P. Vidal, Poesie, col. Documenti di Filologia, 4, Milano-Napoli, Riccardo-Ricciardi, 1960, vol. I, págs. xxxv-xxxix. Para la discusión entorno a este punto y para otras aportaciones, D. S. Avalle-L. Leonardi, op. cit., pág. 36.

7 Véase la edición y estudio de estas rúbricas en V. Bertolucci, «Il canzoniere di un trovatore: il «libro» di Guiraut Riquier», Medioevo Romanzo, 5, 1978, págs. 216-259, así como el estudio del cancionero de este trovador y su estructura en «Libri e canzoneri d'autore nel medioevo: prospettiva di ricerca», Studi Medioltini e Volgari, 30, 1984, págs. 91-116, ambos reimpresos en Morfologia del testo medievale, Bologna, Il Mulino, 1989, págs. 87-124 y 125-146, así como sus "Osservazioni e proposte per la ricerca sui canzonieri individuali», en Lyrique romane médiévale: la tradition des chansonniers. Actes du Colloque de Liège, 1989, Bibliothèque de la Faculté de Philosophie et Lettres de l'Université de Liège, Liège, Université de Liège, 1991, págs. 273-303. Para el estudio de los cancioneros medievales en su conjunto, y en particular los de autor, debe verse también D. S. Avalle, «I canzonieri: definizione di genere e problemi di edizione», en Atti del Convegno di Lecce. 22-26 ottobre 1984, Roma, 1985, págs. 363-382. En este contexto resulta enormemente sugestiva la hipótesis de Amando Petrucci según la cual el proceso de organización de un cancionero personal habría surgido de la experiencia de los notarios, que partían de breves minutas para elaborar después redacciones más complejas de sus actas, revolucionando al establecer este proceso los procedimientos de trabajo de los escritores antiguos («Minuta, autografo, libro d'autore», en Il libro e il texto. Urbino 20-23 settembre 1982, Urbino, Università degli Studi di Urbino, 1984, págs. 397-414.
} 
servados en dos manuscritos en los que se ha supuesto la mano del autor ${ }^{8}$, y otro tanto sucedió con las primeras versiones del Canzoniere petrarquesco: «In planning this form of the collection, Petrarch very naturally set the poems, in general, in the order of the experiences they reflected, in so far as that order remained clear in his mind and seemed to him to be significant» ${ }^{9}$. Entre los cancioneros cuatrocentistas peninsulares conservan este aspecto el de Joan Berenguer de Masdovelles, Biblioteca de Catalunya, ms. 11, el de Juan Álvarez Gato, conservado en la Real Academia de la Historia, ms. 9/5.535, que lleva la sigla $\mathrm{MH} 2$ en los catálogos de Brian Dutton que usaré en adelante ${ }^{10} \mathrm{y}$ los dos de Gómez Manrique, Madrid, Biblioteca Nacional, ms. 7.817 (MN24) y Madrid, Biblioteca de Palacio, ms. 1.250 (MP3).

Donde no cabe la menor duda respecto a una ordenación cronológica es en el cancionero seguramente autógrafo de Joan Berenguer de Masdovelles, ms. 11 de la Biblioteca de Catalunya, donde fueron recogidas las composiciones de este autor y de diversos miembros de su familia y sobre el que espero volver pronto con más detenimiento. Es un manuscrito de letra muy cursiva y descuidada, con una peculiarísima ortografia, ajena a lo que era corriente en la copia de libros y documentos en su época ${ }^{11}$; la factura de sus cuadernos es irregular y algunos están muy estropeados, en particular el primero (a todas luces acéfalo) y el último ${ }^{12}$. El papel parece proceder de

\footnotetext{
${ }^{8}$ Véase Il canzoniere di Nicolò de' Rossi, vol. I, Introduzione, testo e glossario, vol. II, Lingua, tecnica, cultura poetica, edición de Furio Brugnolo, col. Medioevo e Umanesimo, 16 y 30, Padova, Antenore, 1972, en especial vol. II, págs. 9-16. Tradicionalmente se ha visto la intervención directa de la mano del autor en dos de estos cancioneros, especialmente en el precioso ms. 7-1-32 de la Biblioteca Colombina, coetáneo suyo; a pesar de la aceptación tácita de Brugnolo, véanse las reservas expresadas por varias investigaciones, hoy cómodamente recogidas por C. Bologna, "Tradizione testuale e fortuna dei classici italiani», en Letteratura italiana. VI. Teatro, musica tradizione dei classici, Torino, Einaudi, 1986, págs. 445-929, especialmente pág. 529 .

9 Wilkins, «The making of the Canzoniere», pág. 155. También B. Martinelli afirma que «Nelle sue grandi linee l'opera rivela infatti una effetiva strutturazione cronologica ben evidenziabile: alcune serie o gruppi di liriche, intere sezioni del libro sono state costituite su un minimo comun denominatore di trama di cronologia reale» («L'ordinamento morale del Canzoniere del Petrarca», en Studi Petrarcheschi, 8, 1976, págs. 93-167, especialmente págs. 94-95).

${ }^{10}$ Catálogo-índice de la poesía cancioneril del siglo $\mathrm{XV}$, Madison, Hispanic Seminary of Medieval Studies, 1982 y sobre todo su magno Cancionero del siglo XV c. 1360-1520, siete volúmenes, Salamanca, Universidad, 1990-1991. En general, por ofrecer una visión más sintética del contenido de cada manuscrito, citaré por el primero, a pesar de que en la segunda versión suele ofrecer no pocas modificaciones.

${ }^{11}$ Véase la edición del texto en R. Aramon i Serra, Cançoner dels Masdovelles (Manuscrit $n^{\circ} 11$ de la Biblioteca de Catalunya), Barcelona, Institut d'Estudis Catalans, 1938, así como la introducción, donde se estudian diversos aspectos del manuscrito.

${ }_{12}$ El primer cuaderno, en su estado actual, está al parecer compuesto por once bifolios (ff. 7-28 de la numeración moderna), pero antes se observan seis folios sueltos; por otra parte, el primer folio con numeración antigua, con números romanos, el actual 8 , lleva el xi, por lo que debieron perderse algunos. He de señalar también que después del f. 28 (=xxxi), al
} 
alguna fábrica local, pues su filigrana, con la figura de un unicornio ${ }^{13}$, sólo se ha documentado en Cataluña en 1436, una fecha que coincide con el posible comienzo en la composición del manuscrito.

Otro aspecto altamente original de este manuscrito es la tipología de sus rúbricas. A veces son tan largas, tan circunstanciadas y con tantos detalles sobre las anécdotas, a menudo nimias, que las motivaron, que constituyen un testimonio de primer orden para el historiador de la poesía cortés. Unas veces se trata de indicaciones retóricas: «Cansso d'amor, retorguedada per diccions per bordons e per cobbles, la qual, leguint-la pla e retorguedant-la, es la meytat de rims crozats e l'altre maytat de rims plans, es capcaudada per cobbles» ${ }^{14}$, otras dan la fecha de composición, a veces acompañada de precisiones interesantísimas sobre la vida literaria de la época: «En lo mes de juyn any .M.CCCC.XXXVIII., en la ciutat de Barchalona, dona mossen Berthomeu Castello una joha a qui mils se complenyaria d'emor, un se donaren moltes hobre[s], entre les quals n'i dona En Guillem de Masdovelles la seguent, en deffensio del deu d'emor e contra los trobadors qui's compleynien» ${ }^{15}$ y otras, por fin, explicitan como ninguna otra fuente el tipo de vivencias biográficas subyacentes a la producción cortés, uno de los grandes enigmas que envuelven la historia de esta lírica, como la siguiente: «Lo dilluns sant de l'any .XXX. nou, mossen Endreu Despens, he mossen Ffrançesch Marti de Gralla, he jo, Johan Berenguer de Masdovelles, estant en la ciutat de Barçalona, fem novellament aymies, he per tant com per ra-

fin del primer cuaderno actual, sigue otro $(29=$ xxxii) que no es solidario del f. 6 , lo cual demuestra que entre éste y el actual 7 debió perderse alguno más (o que el 29 fue añadido, de lo que se encuentran otros casos a lo largo del manuscrito, sin que casi nunca podamos saber si se deben a interpolaciones o a pérdidas). Aramon (ob. cit., pág. xvi) considera que estos folios iniciales pudieron contener borradores de poemas. Lo que llamo el último cuaderno (ff. 147-152 tras los que se encuentra un folio final) son en realidad seis folios hoy sueltos, aunque la disposición de las filigranas permite suponer que pudieron ser solidarios. Aparte de otras anomalías de menor entidad, como los folios hoy sueltos, hay que señalar el casi total desballestamiento de lo que considero cuaderno tercero (ff. 53-65).

${ }^{13}$ La identificó Aramon en la pág. XVI de su estudio, y aparece registrada por Francisco de A. de Bofarull y Sans, Los animales en las marcas de papel, Vilanova i Geltrú, 1910, pág. 131. Hay una segunda filigrana que aparece exclusivamente en el folio final del manuscrito, conservado hoy suelto y sin otra hoja solidaria en la primera parte del cuaderno, sin escritura, aunque con diversas pruebas de pluma coetáneas, con unas tijeras que pueden identificarse con la número 3661 de Ch. M. Briquet, Les filigranes. Dictionnaire historique des marques du papier, edición facsímil de Leipzig, 1923, Hildesheim-New York, Georg Olms Verlag, 1977, y con el n. ${ }^{\circ} 1788$ de O. Valls i Subirà, Paper and Papermarks in Catalonia, Amsterdam, The Paper Publications Society, 1970, que el primero data en Venezia en 1438 y el segundo en 1416. A pesar de su aspecto a primera vista sospechoso respecto a la constitución del cancionero, esta hoja, a juzgar por su datación, pudo pertenecer al mismo desde el primero momento.

${ }^{14}$ f. 11 r, edición citada $n .^{\circ} 3$.

15 f. 34 r, edición n. ${ }^{\circ} 41$. 
ho de les festes de Pasqua aviem a partir de la dita ciutat per anar en nostres cases, acordam que y tornassem en lo mes de mayg apres seguent; he jo, durant lo temps que fom fora la dita ciutat tots tresos, fiu les cobbles seguens, he aquelles tremati als dits mossen Endreu he mossen Gralla, a Lleyda, on es llur abitassio, he sso per tant com jo sens ells no podia tornar a la dita ciutat, ans los avia esparar a l'Arboç, hon ells davien venir» ${ }^{16}$, o como ésta, donde describe las pequeñas miserias en una riña entre amantes: «La cobbla devall escrita tremati jo, Johan Berenguer, a un meu cossi qui amava una dona, la qual avia a sa volentat, he sabie u jo; he sobre una trena que ella avia feta dels seus cabells, la qual lo dit mon cossi li demena, ells se barallaren, car ella no la·y volch donar, ans li dix que li paguas dues camisses que li avia donades, les qual aquell havia ja rompudes, e mes que li paguas ho li tornas un diamant que li avia donat, he partiren-se fort mal. He per la dita raho jo tremati-li la dita cobbla, a la qual me respos no en rims, car no sap de trobar, preguant-me li fes un maldit sobre lo dit cas; he fiu-ne dos (...) Ffeu-se a .X. de maig de l'any .XXXVIII.» ${ }^{17}$ o esta otra, sobre un amor escasamente afortunado: «La cobbla devall scrita ffiu jo, dit Masdovelles, ssobre lo cas seguent: Dues dones anaven ensemps de companyhia, he la una dix a l'altre: 'Vet assi que ve Masdovelles. Coneixs-lo?' He l'altre respos que ssi. Replica l'altre, dient: 'De tu es anamorat; dies ha que jo.u conech. No se tu ssi n'as aguda conaxença'. He aquella dix que be u conaxia, mas que ella no m'o podia vedar» ${ }^{18}$. Aparte del interés narrativo de alguna de estas rúbricas, que parecen episodios del Novellino, resultan inestimables para conocer la vida cortés, el significado real de este tipo de poesía y su función en la vida social del siglo XV; pero, sobre todo, nos certifican que, sea o no autógrafo el cancionero, como se venía suponiendo hasta ahora, la información contenida sólo puede proceder del propio Joan Berenguer de Masdovelles. Recuérdese que este mismo fenómeno se da en las rúbricas a las canciones de Guiraut Riquier, Raimon Gaucelm y Johan Esteve entre los trovadores provenzales, así como otro autor catalán de la época de Masdovelles, Antoni Valmanya, y siempre han dado lugar a suponer que, si los datos contenidos no pueden extraerse del texto mismo del poema de-

\footnotetext{
${ }^{16}$ f. 58 r, edición n..$^{\circ} 66$. Recuérdese que en 1'Arboç es donde tenía sus dominios el autor. Véase R. Conde Delgado de Molina, «Dades sobre la familia dels Masdovelles», Estudis Universitaris Catalans, XXV, Estudis de Llengua i Literatura Catalanes oferts a Ramon Aramon $i$ Serra en el seu setantè aniversari, Barcelona, Curial, 1983, vol. III, págs. 81-96. Tiene menos interés V. Carbonell i Virella, "Els Masdovelles, llinatge del Penedès», Miscel-lània Penedesenca, 1, 1978, págs. 17-27.

17 f. $67 \mathrm{v}$, edición n. 86

${ }^{18}$ f. $106 \mathrm{v}$, edición n. ${ }^{\circ} 131$.
} 
ben proceder, inevitablemente, del autor ${ }^{19}$. Entre otros detalles, las rúbricas de nuestro manuscrito tienden a darnos la fecha en que fueron compuestas. $\mathrm{Su}$ relación da el siguiente resultado:

\begin{tabular}{lll}
\hline Número & \multicolumn{1}{c}{ Fol. } & Fecha \\
\hline $41-42$ & xxxiv r.-v. & 1438 \\
66 & lviij r. & 1439 \\
$86-88$ & lxvij v. & 1438 \\
137 & cxij v. & 1443 \\
138 & cxiij r. & 1389 \\
139 & cxiij v. & 1394 \\
161 & cxxxviiij r. & 1458 \\
$162-163$ & cxxxxj r.-cxxxxiij r. & 1460 \\
165 & cxxxxiii v. & 1461 \\
166 & cxxxxvj r. & 1464 \\
$168-169$ & cxxxxviij v.-cl r. & 1465 \\
170 & cl v. & 1467 \\
171 & clvj r. & 1464 \\
172 & clvj r. & 1465 \\
\hline
\end{tabular}

Respecto a los números 138 y 139, tan descolocados, la razón es muy simple: se trata de dos composiciones de Guillem de Masdovelles, tío del colector del cancionero, cuya datación resulta indudable a la luz de los hechos históricos que las rúbricas explicitan ${ }^{20}$ y que éste introdujo en un momento cuyas motivaciones no podemos hoy precisar aunque, a tenor de la atención que Joan Berenguer prestaba a los acontecimientos políticos coetáneos, bien pudieron estar relacionadas con hechos recientes ${ }^{21}$. Como se puede ver, las disonancias entre la

${ }^{19}$ Para los trovadores provenzales Guiraut Riquier, Johan Esteve y Raimon Gaucelm, véase su edición en V. Bertolucci en «Il canzoniere di un trovatore», ed. cit., págs. 122-124; la obra del segundo de estos trovadores ha sido editada por S. Vatteroni, Le poesie del trovatore Johan Esteve, Biblioteca degli Studi Mediolatini e Volgari. Nuova Serie, 10, Pisa, Pacini, 1986, que se ocupa de las rúbricas en 16-22 del estudio preliminar. Para Antoni Vallmanya, cuya obra aparece contenida en varios cancioneros, véase el estudio de J. Auferil, «La Sort d'Antoni Vallmanya i el cercle literari de Valldonzella», en Studia in honorem prof. M. de Riquer, vol. I, Barcelona, Quaderns Crema, 1986, págs. 37-77 y su descripción de los manuscritos en su edición de F. Ferrer, Obra completa, Barcelona, Barcino, 1989.

${ }^{20} \mathrm{El}$ primero fue compuesto «en lo temps de la guerra dels armenyaguesos», el segundo, «al cjtj de Catanja, per manament del duch de Monblanch, l'jnffant don Martj, quj apres fonch rey d'Araguo»; Para la datación véase J. Rubió i Balaguer, Història de la literatura catalana, publicada primero en edición castellana en la Historia general de las literaturas hispánicas dirigida por G. Díaz Plaja, Barcelona, 1948-1959, que cito por la traducción catalana publicada con este título en Barcelona, Publicacions de l'Abadia de Montserrat, 1984, vol. I, págs. 210-211, así como M. de Riquer, Història de la literatura catalana, segunda edición corregida, Barcelona, Ariel, 1980, vol. III, págs. 683-684.

${ }^{21}$ A pesar de la extremada diferencia entre la datación de los poemas que los anteceden y siguen (1443-1458) no me parece difícil identificar estas circunstancias. Espero ocuparme en breve de estos problemas. 
ordenación interna del cancionero y la cronología son de escasa entidad (números 66 y 86-88) y las más considerables afectan a sólo dos poemas (números 170 y 171-172); si consideramos que el último (172) es de tipo religioso, como las escasas composiciones que lo siguen hasta el fin del manuscrito (173-176, ff. clv r.-clxj v.), podremos suponer que, en un momento determinado, cuando su atención se había volcado ya sobre estos temas, el autor recuperó una composición anterior. Para estos casos hemos de conjeturar cierta distancia entre la composición y su incorporación definitiva al manuscrito, de lo que, en este caso particular, tenemos un indicio muy valioso, aunque de interpretación equívoca, en la rúbrica al número 172 , uno de los textos de datación más discordante: «La hobre devall scrita he feta jo Johan Berenguer de Masdovelles sobre la fe en lo mes de març ay .lxv. l'ascrivi en lo present libre» (f. 157 r.). Si hacemos pausa después de la fecha, el autor estaría haciendo notar que el lugar de transcripción no coincide con el que le correspondería por su cronología, sino que nos hallaríamos ante una obra de 1465 transcrita en su libro con posterioridad ${ }^{22}$; en cualquier caso, esta rúbrica se explica mejor si pensamos que el autor pretendía dejar constancia expresa de que creación y transcripción no fueron inmediatas. Hemos de añadir que la transcripción de una obra en el cancionero de su autor no se ejecutaba necesariamente, pues de cualquiera de los poetas que nos legaron cancioneros de autor (y lo mismo sucede con Joan Berenguer de Masdovelles) existen obras recogidas en las antologías coetáneas y ausentes en su propia compilación. Recordemos las palabras del Marqués de Santillana cuando el condestable don Pedro de Portugal le pidió su cancionero: «de unas e otras partes, e por los libros e cançioneros agenos, [las] fize buscar e escriuir» ${ }^{23}$.

La investigación historiográfica ${ }^{24}$ ha ido datando otras composiciones que dan la secuencia siguiente:

\begin{tabular}{clc}
\hline Número & \multicolumn{1}{c}{ fol. } & Fecha \\
\hline 185 & lxxxxv v. & 1467 \\
145 & cxxij r. & 1464 \\
148 & cxxv r. & $1459-1467$ \\
158 & cxxxv r. & 1451 \\
164 & cxxxxiij v. & 1460 \\
167 & cxxxxij v. & 1464 \\
\hline
\end{tabular}

\footnotetext{
${ }^{22} \mathrm{La}$ interpretación del editor es que fue en este año cuando la composición fue copiada, y así pone punto y coma después de «la fe». Nótese sin embargo que así esta composición se convierte en una de las dos únicas piezas cuya datación está notablemente descolocada en el manuscrito y se incurre en la inconsecuencia de que ésta hubiera sido transcrita en el manuscrito después que lo fuera la número 170, datada en 1467.

${ }^{23}$ El prohemio e carta del marqués de Santillana y la teoría literaria del siglo XV, edición crítica, estudio y notas de Ángel Gómez Moreno, Barcelona, PPU, 1990, cit., pág. 52.

24 J. Rubió i Balaguer, ob. cit., págs. 429-432 y M. de Riquer, ob. cit., vol. III, págs. 133-144.
} 
En conjunto suscitan más dudas, lo cual no tiene nada de particular si atendemos a los detalles nimios sobre los que casi siempre nos vemos obligados a trabajar para estos menesteres. Una limitación a la que no escapan las circunstancias que concurren en los números 145 y 148 pues, si bien los hechos históricos aducidos por los investigadores parecen hechos a medida de las alusiones contenidas en los poemas, éstas pudieron deberse a acontecimientos distintos, mal conocidos, o a sucesos irrelevantes o sobre los que carecemos de información o, incluso, a otros perfectamente datados e identificables sobre los que todavía no hemos reparado. Muy distinto es el caso del texto contenido en el $\mathrm{f}$. lxxxxv v., pues se trata, por razones paleográficas, de una interpolación posterior ${ }^{25}$. En cualquier caso, aún admitiendo como ciertas y seguras todas las discordancias señaladas y como ajenas al caso las explicaciones aducidas para algunas de ellas, quedaría patente que el cancionero de Joan Berenguer de Masdovelles ha de entenderse en su conjunto como un testimonio cronológicamente ordenado de la producción de este autor.

Un tanto más complejo resulta el caso de los tres cancioneros que nos han conservado la obra de Gómez Manrique, dos de los cuales salieron, muy probablemente, de su propio scriptorium; Juan C. López Nieto ha efectuado un cuidado análisis codicológico en vías de publicación, y de él y de mi propio estudio de los manuscritos ${ }^{26}$ extraeré los datos más relevantes para esta investigación. Según este autor, MP3, por su contenido, debe ser posterior al 28 de agosto de 1481, pues se menciona como muerto a Alfonso V de Portugal, pero anterior a la redacción de la Consolatoria a

${ }^{25}$ En efecto, la breve composición que figura en el $\mathrm{f}$. lxxxxv v. Aramon la publica con el número 185 (n. ${ }^{\circ} 119$ en la relación de J. Massó Torrents, «Bibliografia dels antics poetes catalans», Anuari de l'Institut d'Estudis Catalans, 5, 1913-1914, págs. 2-275, que sigue el orden de manuscrito) y data de 1467. Por sus breves dimensiones, pudo haber sido añadida en este folio que, como el siguiente, lxxxxvj r., quedarían en blanco, tal como siguen hoy a excepción de estos cinco versos. De hecho, la letra de los ff. lxxxxiij v.-lxxxxv v. es mucho más irregular y descuidada que en la primera parte del manuscrito, hasta el $\mathrm{f}$. cxiiij r. Después se parece ya muchísimo a la del f. $\operatorname{xxxxv} v$., aunque la tonalidad de la tinta es a trechos más clara, a trechos como la de este texto.

${ }^{26}$ Para MP3 me baso exclusivamente en su trabajo; para MN24 y MN29, del que me ocuparé más adelante, me baso especialmente en mi estudio del manuscrito, aunque la identificación de las filigranas sea de J. C. López Nieto. Como es lógico, no pretendo tampoco en este caso una descripción completa del manuscrito, lo que interferiría además sus investigaciones, sino sólo aprovechar algunos de sus datos, los más significativos, en la reconstrucción de las características que resultan comunes a los cancioneros de autor; para lo demás, habrá que esperar la edición de sus materiales cuya generosa comunicación agradezco al autor. Véanse también las descripciones sumarias de A. Paz y Melia en las págs. xxxvi-xxxviii de la introducción a su Gómez Manrique, Cancionero, dos volúmenes, Madrid, 1885-1886, del que hay excelente reproducción facsimilar que antepone el trabajo de M. Carrión, "Gómez Manrique y el protonotario Lucena, con dos cartas en memoria de Jorge Manrique», en Palencia, Excma. Diputación Provincial de Palencia, 1991. 
su muger, datable después de agosto de 1484 por su alusión a la muerte del duque de Viseo, que sí será incluida en MN24; por otra parte, y si aceptamos la dependencia del autor, ambos han de ser anteriores a su muerte, que tuvo lugar entre el 31 de marzo de 1490, en que otorga testamento, y el 16 de febrero de 1491 , en que se sacó una copia autorizada del mismo ${ }^{27}$. Esta datación es coherente con la información contenida en las filigranas. En efecto, tal como demuestra J. C. López Nieto, MP3 contiene varias marcas de papel que, en conjunto, sugieren una datación de hacia 1470-1490. Copiado sobre quiniones, cuyos bifolios interior y exterior son de pergamino, su cuidada ejecución es de sobra conocida.

MN24, posterior como queda dicho a agosto de 1484, ofrece distintas filigranas, todas pertenecientes al tipo de mano con guantelete, no siempre identificables. En conjunto, pueden datarse en el período 1480-1492, especialmente en el tramo que va de 1488 a 1492 . Se trata de un manuscrito muy cuidado, compuesto originariamente por seniones cuyos bifolios interior y exterior debieron ser siempre de pergamino; hoy faltan muchos de ellos, así como otros folios, que debieron caer al faltarles esta protección, especialmente en los cinco primeros cuadernos, muy estropeados. El papel, que mide hoy $290 \times 198$, fue alisado cuidadosamente antes de proceder a su escritura. Copiado en una bella letra gótica de gran módulo, a sólo tres estrofas por página, está decorado con rúbricas en rojo y bellos calderones, de grandes dimensiones que alternan los colores azul y rojo, al inicio de cada estrofa. En conjunto es uno de los más bellos cancioneros de mano castellana, y no desmerece de la categoría de don Gómez ni de la de su destinatario, don Rodrigo Pimentel, conde de Benavente.

En conjunto, y como puede observarse, ambos comparten rasgos comunes en su manufactura, en particular la composición de sus cuadernos mediante bifolios interior y exterior de pergamino, un recurso de origen humanístico poco frecuente en los cancioneros castellanos, y la copia a tres estrofas por página, propia de los cancioneros más cuidados. Por otra parte, la datación del papel coincide con la cronología de los textos contenidos, y todo ello nos sitúa en los últimos años de vida don Gómez. Creo que la hipótesis de que nos hallamos ante sus propios originales, copiados por encargo suyo para agasajar a sus amigos, es más que aceptable. En este sentido, es significativo que tanto MP3 como MN24 estén encabezados por una epístola a D. Rodrigo Pimentel, conde de Benavente, lo mismo que

${ }^{27}$ Véase L. de Salazar y Castro, Historia genealógica de la casa de Lara, Madrid, Imprenta Real, 1696-1697, vol. II, libro XII, cap. I, donde traza la biografia del poeta, especialmente, págs. 538-571 y las Pruebas o documentos que aduce, publicados en el lugar del tomo IV que allí se indica. 
el marqués de Santillana adoptó el Prohemio e carta al condestable de Portugal para encabezar los manuscritos de sus obras.

También pudiera haber salido del taller de Gómez Manrique un tercer cancionero del que no nos queda sino un fragmento de 43 folios, conservado en la Biblioteca Nacional de Madrid, ms. 10.047 (MN29), que López Nieto, a partir de las relaciones políticas entre los Manrique y los Mendoza, data hacia 1459-1460; en ningún caso será posterior a 1468 , año en que Pero González de Mendoza, a quien va dedicado en su epístola inicial (y cuyo nombre y cargo ocupan la bella rúbrica en rojo que abre el cancionero) fue transferido del obispado de Calahorra al de Sigüenza. De grandes dimensiones $(371 \times 257 \mathrm{~mm}$ ), copia a dos columnas de cuatro estrofas por página; la letra es del tipo semigótica, un tanto desigual en la inclinación de los ástiles y de módulo un poco alto, de trazo un tanto vacilante, aunque revela la mano de un copista muy avezado, bellamente adornada por rúbricas en rojo y calderones. Las filigranas apenas son visibles, aunque alguna de ellas puede identificarse con la figura de una flor datable hacia 1460 , lo cual nos priva de un interesante medio de verificación de nuestras hipótesis. Si el emparejamiento de los tres manuscritos es válido (no olvidemos que en la parte final de este cancionero hay fragmentos de obras de Fernán Pérez de Guzmán cuya presencia se debería justificar), nos hallaríamos en una fase de la elaboración del cancionero personal de Gómez Manrique anterior a las que antes estudiábamos ${ }^{28}$.

El fragmento de cancionero dedicado a Pero González de Mendoza, tras la epístola de envío, empieza por el planto a la muerte del marqués de Santillana; nada más apropiado para abrir una colección dedicada a su hijo, cuyo recuerdo encabeza también la carta: «Sy Despues dela defunssion del muy virtuoso padre vuestro...». El resto, por breve y fragmentario, vuelve muy difícil construir alguna hipótesis sólida. Los otros dos cancioneros de Gómez Manrique, en su organización interna, dan una impresión de caos que sorprendió ya a su primer editor: «bien hubiera querido ordenar las [poesías] de este cancionero por sus respectivos géneros, por lo menos, a la manera que se hallan en el general de Hernando del Castillo, para que no

\footnotetext{
${ }^{28}$ Los datos expuestos, en particular la distinta factura entre este manuscrito y los dos anteriores y la existencia de poemas de Fernán Pérez de Guzmán al final, tendrían explicación muy fácil si supusiéramos que no se trata del original, sino de una copia complementada por composiciones ajenas. Para estos procedimientos véase mi «La organización de los materiales», citado en la nota 1 . Mientras no sea posible datar con precisión el papel y decidir si la última parte pertenece a la misma factura, el problema quedará sin solución; en cualquier caso no se olvide que nos hallamos ante un fragmento, lo cual complica todavía más el problema al no ser posible la reconstrucción de su estado original. Ha de tenerse en cuenta también, según me indica J. C. López Nieto, que este manuscrito procede de la biblioteca del cabildo toledano, por lo que muy bien pudo haber pertenecido a Pero González de Mendoza.
} 
apareciese una composición profana, o tal vez burlesca, junto a otra sagrada, o dirigida a llorar casos de lástima» ${ }^{29}$. La solución, probablemente, la obtendremos si atendemos a la vez a su orden y a su cronología ${ }^{30}$ :

\begin{tabular}{rrrcc}
\hline MP3 & MN24 & MN29 & Edición & Año \\
\hline & 35 & & 27 & 1484 \\
47 & & 34 & 1453 \\
49 & 42 & 4 & 36 & 1455 \\
58 & & 50 & $1456-58$ \\
79 & 64 & 2 & 67 & 1458 \\
& 70 & & 42 & -1474 \\
95 & 74 & & 44 & 1464 \\
96 & 100 & 81 & 1468 \\
97 & 101 & & 82 & $1466-68$ \\
100 & 102 & & 82 & 1467 \\
& 105 & & 108 & $1469-1478$ \\
117 & 112 & 93 & 1467 \\
119 & 113 & & 94 & 1473 \\
133 & 115 & & 104 & $1474-1474$ \\
\hline
\end{tabular}

Como se puede observar, y con pocas vacilaciones, la obra de Gómez Manrique tiende a una disposición cronológica en los dos cancioneros. El poeta, en la preparación de estos ejemplares o de su arquetipo, debió partir de un cuaderno personal, sin otro orden que el de la copia sucesiva de los poemas $\mathrm{y}$, por ende, en gran medida cronológico, que reproduciría sin mayores complicaciones. Las variaciones de uno o dos años (números 105-112 de MN24) podrían deberse a un olvido o postergación del poema más antiguo en el momento de su copia en el cuaderno personal del autor, o de alteraciones producidas al pasar estos textos a la copia conservada o a su arquetipo. Por otro lado, sólo existe una disonancia grave, el número 35 de MN24 (la Consolatoria a su mujer), aunque hay que tener en cuenta que esta parte del manuscrito presenta diversas irregularidades que permiten dudar de su integridad o de su coherencia con el plan inicial ${ }^{31}$. Esperemos

29 Paz y Melia, ob. cit., pág. xxxv.

30 Para establecer la cronología me he basado en las notas a la edición de Paz y Melia, cuyo número consta en la columna respectiva, y en algunos datos que me parecieron obvios, así como algunos más que recojo de la descripción de J. C. López Nieto. Espero que su edición aporte más elementos útiles para este fin. Respecto a la numeración de los poemas según su aparición en los manuscritos, como haré siempre en el resto de los estudiados, acepto los índices de Dutton a pesar de sus frecuentes inconsecuencias, pues constituyen un referente cómodo.

31 Ya Dutton anota la falta de folios; pero no es este el único problema, como se observa en el trabajo de J. C. López Nieto. 
que más investigaciones sobre estos pormenores aporten nuevos datos que permitan confirmar o rectificar la hipótesis que aquí presentamos; en cualquier caso, tras el precedente de Joan Berenguer de Masdovelles, y sobre el trasfondo de los Liederblätter trovadorescos de que arriba nos hacíamos eco, no cabe la menor duda de que los manuscritos de autor ordenados cronológicamente existieron y que fueron la fuente original de sus compilaciones, y éste es el punto nuclear de los problemas que hasta este punto hemos venido discutiendo.

El cancionero de Juan Álvarez Gato no es, ni mucho menos, desconocido para la crítica ${ }^{32}$; falta, sin embargo, una descripción y estudio cuidado con criterios paleográficos y codicológicos, como viene sucediendo, como regla general, para el conjunto de los cancioneros castellanos y que, por razones obvias, no realizaremos aquí. Mide 298 x $204 \mathrm{~mm}$, de compaginación muy irregular, de entre una y tres estrofas por página, según la extensión del poema. La letra, una gótica muy cuidada y semejante a la del Cancionero de Baena, va disminuyendo progresivamente su caja a partir del f. 70 . La misma mano que copió el texto trazó una numeración por cuadernos que va desde avij (= f. 3 de la numeración moderna) hasta kxiiij (=151); hay una numeración antigua a números romanos, pero debió ejecutarse cuando el manuscrito había perdido ya buena parte del cuarto cuaderno. Los cuadernos debieron ser todos de catorce bifolios, aunque hoy han sufrido numerosas mutilaciones. La mayoría de las hojas carecen de preparación para la escritura o de pautado y cuando existe se trata de un sencillo rectángulo a punta seca, más apropiado para textos en prosa; éste se encuentra regularmente en la segunda parte del manuscrito, que contiene la obra prosística del poeta. Como ya observó Artiles, el papel es rigurosamente uniforme para todo el manuscrito, con una sola filigrana, una mano con estrella que coincide con el n. ${ }^{\circ} 11.151$ del repertorio de Charles Briquet, datada en Italia y Francia entre 1470 y 1480.

Este dato ayuda a confirmar la hipótesis tradicional de que nos hallamos ante el manuscrito original del poeta que, a juzgar por las observaciones y notas que contiene, fue conservado por su familia. Artiles no creía que fuese autógrafo y atribuía la copia a sus sucesores, pues en las rúbricas se habla del autor en tercera persona y la que precede el $n .^{\circ} 64$ de su edición

\footnotetext{
${ }^{32}$ Fue publicado por José Artiles Rodríguez en las Obras completas de Juan Álvarez Gato, Los clásicos olvidados, 4, Madrid, 1928 (aunque con un cambio en el orden de los poemas; el original, como de costumbre, puede seguirse a través del índice de B. Dutton), que lo describió en las págs. xxxii-xxxvi, y estudiado por F. Márquez Villanueva, Investigaciones sobre Juan Álvarez Gato. Contribución al conocimiento de la literatura castellana del siglo $\mathrm{XV}$, Anejos del Boletín de la Real Academia Española, 4, Madrid, Real Academia Española, 1960, que cito por la segunda edición revisada y ampliada de 1974, especialmente págs. 202-204.
} 
especifica que «de vn tratado que hizo sobre esto no se hallan agora mas destas dos coplas» (f. 49 r.) ${ }^{33}$. Márquez Villanueva, por el contrario, y a juzgar por el mismo indicio, cree que «la recopilación de su poesía debió de ser hecha por el autor en fecha bastante avanzada, cuando encontraba ya dificultades insolubles para recuperar algunos textos» ${ }^{34}$; recordemos que el marqués de Santillana se hacía eco de una dificultad semejante cuando se vio obligado a recoger «por los libros e cançioneros agenos» las obras que le había pedido el condestable de Portugal ${ }^{35}$. De ahí que, basándose, con mejor criterio, «en las rúbricas, distintas de las que aparecen en colecciones generales, minuciosamente circunstanciadas, con detalles que sólo él podía proporcionar» ${ }^{36}$, Márquez Villanueva concluía autorizadamente que se trata de un autógrafo. La datación del papel, ya avanzada en el transcurso de la producción de nuestro poeta, refuerza sus hipótesis.

La poesía de Juan Álvarez Gato permite escasas precisiones cronológicas, pero en conjunto corrobora la imagen de un cancionero copiado por este orden. Véase el siguiente cuadro ${ }^{37}$ :

\begin{tabular}{rrc}
\hline Ed. & MH2 & Fecha \\
\hline 13 & 2 & -1472 \\
38 & 29 & $1455-1464$ \\
41 & 32 & $1455-1464$ \\
42 & 33 & $1455-1464$ \\
43 & 34 & $1455-1464$ \\
55 & 47 & -1474 \\
56 & 48 & 1466 \\
63 & 58 & $c .1465$ \\
64 & 59 & $1462-64$ \\
65 & 60 & -1474 \\
66 & 61 & -1474 \\
73 & 68 & 1471 \\
84 & 80 & -1474 \\
91 & 88 & $1482-1491$ \\
102 & 100 & -1492 \\
72 & 105 & $1474-$ \\
\hline
\end{tabular}

${ }^{33}$ Ob. cit. pág. xxxii y nota.

${ }^{34}$ Ob. cit., pág. 203.

35 Prohemio e carta, ed. cit. pág. 52.

${ }^{36}$ Ob. cit., pág. 202.

${ }^{37}$ Para fijar la cronología, reúno datos de Ruffini, Observaciones filológicas sobre la lengua poética de Juan Álvarez Gato, Sevilla, Editorial Católica, 1953, pág. 9 nota y Márquez Villanueva, ob. cit., pág. 263-266, que las resume y aporta numerosos datos nuevos. Pero la n. ${ }^{\circ} 72, \mathrm{MH} 2$ 105, que Márquez Villanueva data entre 1455-1464 creyéndola dedicada a Juana de Portugal, esposa de Enrique IV, lo está en realidad a Isabel la Católica, pues en el v. 36 habla de «seis letras 
Otro factor a tener en cuenta es la rúbrica que abre la segunda parte del cancionero, dedicada básicamente a temas piadosos: «aujendo conosçido el mundo y (...) gustado mucho de lo que se procura del y visto ques todo condenaçion del anjma y en los catolicos dolor y arrepentimjento (...) deseando desnudarse de todas las vanjdades afeçiones y lisonjas ca segujdo y malos enxenplos que ha dado viçiosos y pecadores (...) penso de pelear con nuestros tres contrarios [o sea, mundo, demonio y carne] en cuyo poder se hallaua con esperança que con los medios dela graçia de nuestro Señor (...) los vençeria y se vestiria de nueva ropa de virtudes desde su temor y amor» ${ }^{38}$. Márquez Villanueva estima que este proceso debió tener lugar hacia $1471^{39}$, momento anterior, a juzgar por la cronología del papel, a la composición del manuscrito. Enseguida veremos la importancia que tienen estos datos.

A pesar de esta aparente ordenación cronológica, las cosas no parecen tan sencillas en el caso de este cancionero. En efecto, resulta demasiado brusco el corte entre una poesía del pecado, anterior a su conversión, y una poesía de la virtud, a la que se habría dedicado casi exclusivamente después de 1471. La vida suele ser más compleja que las creencias o el arte. La segunda sección, tras la rúbrica que copiábamos más arriba, comienza con un poema destinado a marcar una ruptura irrevocable: «mundo (...) yo te despido de my», después del cual aparece una apostilla en prosa: «Daquj adelante no hay cosa trobada nj escrita syno de deuoçion y buena dotrina» ${ }^{40}$. Por fin, el cancionero se cierra con otra copla donde retoma la estructura bifronte de la compilación: «Porque comjença este libro en coplas viçiosas damores pecadoras y llenas de moçedades y prosigujendo habla en cosas de rrazon y al cabo esprituales, prouechosas y contemplatiuas hizo el que le escriujo esta copla. // Este libro (...) la meytad es de verdades / la otra de vanjdades...» ${ }^{41}$. La condición de acéfalo que afecta al manuscrito impide dilucidar si había una composición de apertura de carácter específico.

\footnotetext{
negras de amores», lo cual conviene al nombre de la segunda, no de la primera; para el prejuicio, totalmente infundado, de creer que Isabel rechazaba las veleidades de los poetas cortesanos y sus excesos, véase R. O. Jones, "Isabel la Católica y el amor cortés», en Revista de Literatura, 21, 1962, págs. 55-64, que ya se apercibió de este dato; sin embargo, disiento de él en considerar dedicadas a la Reina Católica también los números 38-43 que, como demuestra la estructura cronológica del códice, han de pertenecer al período de Enrique IV. Nada tiene de extraño que Juan Álvarez loara a dos reinas consecutivas en los mismos términos. En el cuadro anterior, la columna relativa a la edición, por supuesto, reproduce el número que cada poema tiene en la de Jenaro Artiles; en cuanto a su posición en el manuscrito, me atengo a la numeración que les da Dutton, aunque no siempre sea consecuente con sus criterios, a fin de evitar equívocos.

${ }^{38}$ f. 60 v. que puede verse en la Edición cit. n..$^{\circ} 73$. Antecede al n. ${ }^{\circ} 68$ del manuscrito y 73 de la edición.

39 Ob. cit., pág. 266.

${ }^{40}$ Ed. cit., n. ${ }^{\circ} 73$, que cito directamente del f. 60 v. del manuscrito.

${ }^{41}$ Ed. cit., n. ${ }^{\circ} 104$, que cito directamente por el folio $138 \mathrm{v}$. del manuscrito.
} 
Por último, quizá sea procedente recordar en este punto el caso de Guittone d'Arezzo, cuya obra aparece dividida, probablemente por el mismo autor, bajo dos rúbricas distintas: "Guittone», que contiene la obra profana, y «Frate Guittone», con la producción posterior a su conversión y su ingreso en la orden de los «Milites Beatae Virginis Mariae» ${ }^{42}$.

Estos datos recuerdan vivamente lo que sucede con otro cancionero de autor al que nos hemos referido más arriba, el de Guiraut Riquier. Como decíamos en su momento, el orden de las cansos y vers, junto con otros géneros menores que se van intercalando, como las pastorelas, es el cronológico, pero hay un hito significativo: en 1283, el autor alude a la muerte de Belh Deport, la única dama que había cantado, introduciendo un hiato entre la obra anterior, donde dominaba el amor, y la posterior, donde éste se vertía a lo divino y, bajo el mismo senhal, se dirigía a la Virgen. La última canción amorosa, datada en 1289, sitúa este canto en el pasado; la última composición del libro, por su parte, de 1292,' "proclama addiritura la cessazione di ogni canto, incompatibile con il mondo contemporaneo e con i grandi problemi della cristianità» ${ }^{43}$. No olvidemos, por último, la fértil sugerencia de Valeria Bertolucci que, en el trasfondo del experimento compositivo desarrollado por este trovador provenzal, sitúa el precedente de las Cantigas de Santa Maria, dotadas también de un orden interno rigurosamente calculado que Guiraut Riquier pudo conocer durante su larga y fértil estancia en Castilla, al servicio de Alfonso $\mathrm{X}^{44}$. Nuestro conocimiento de su cancionero ha experimentado un cambio esencial tras la investigación de M.-A. Bossy ${ }^{45}$; a pesar de su orden cronológico, aparentemente natural y producto del azar, la estructura de la

\footnotetext{
${ }^{42}$ L. Leonardi, «Guittone nel Laurenziano. Struttura del canzoniere e tradizione testuale», en La Filologia Romanza e i codici. Atti del convegno Messina, Università degli Studi, Facoltà di Lettere e Filosofia, 19-22 de dicembre 1991, vol. I, págs. 443-480, especialmente págs. 451-454. El autor subraya que, en el conjunto de los manuscritos, «a questa ricorrente bipartizione del corpus non corrisponde però una omogenea distribuzione dei testi sotto le due rubriche», lo que atribuye «una situazione non ben definita nei piani alti della traizione» (pág. 453); me pregunto si no se tratará, al menos en parte, de distintos estadios en su reorganización atribuibles al propio autor. Para este acontecimiento biográfico, C. Margueron, Recherches sur Guittone d'Arezzo, Paris, PUF, 1966, pág. 22 y L. Leonardi en su introducción a G. d'Arezzo, Canzoniere. I sonetti d'amore del codice laurenziano, Nuova raccolta di classici italiani annotati, 13, Torino, Einaudi, 1994, pág. XIII.

${ }^{43} \mathrm{~V}$. Bertolucci, «Il canzoniere di un trovatore», que cito por la reimpresión en Morfologia del testo medievale, esp. pág. 118.

${ }^{44}$ Véase, de la misma autora, «Libri e canzioneri d'autore nel Medievo», arriba citado, especialmente en su segunda mitad. Recuérdese que, como es bien sabido, las Cantigas de Santa Maria, narrativas en su conjunto, sitúan una composición lírica en el lugar correspondiente a las decenas, y abren y cierran la compilación con prólogos y epílogos.

45 "Cyclical Composition in Guiraut Riquier's Book of Poems», en Speculum, 66, 1991, págs. 277-293. Las conclusiones de su análisis aparecen esquematizadas en las págs. 292293, aunque el análisis detallado contiene precisiones sorprendentes que no pueden ser pasadas por alto.
} 
sección lírica («vers» o composiciones morales y «cansos» amorosas) contiene una cuidada estructura basada simultáneamente en una bipartición y una tripartición. Cada una de las secciones resultantes distribuye la proporción de ambos géneros según una ratio prefijada, y sitúa un poema técnica y matemáticamente clave en los puntos de sutura, marcados también, en algunos puntos, por la naturaleza de las rúbricas. El resultado es un portento de organización basada en la simbología de los números y destinada a subrayar, como indicaba V. Bertolucci, el proceso de conversión religiosa del autor.

No nos dejemos engañar: bajo la aparente ordenación cronológica, a menudo emergen reestructuraciones a posteriori de intención interpretativa que tratan de dar un sentido al devenir de la vida y de su trasmutación poética y parece que la idea de organizar y publicar las propias obras en una etapa avanzada de la vida de los autores ha sido una constante. Si las dataciones propuestas por Juan C. López Nieto son correctas, como hoy parece, Gómez Manrique en sus últimos años copió dos veces su cancionero y, aunque carecemos de datos para atribuirle un proyecto de estas características, algo parecido hubo de pasar por su cabeza, a juzgar por la anteposición a modo de prólogo de la carta dedicatoria al conde de Benavente ${ }^{46}$. También del de Guiraut Riquier se desprende que en la última fase de su vida sintió la imperiosa necesidad de ordenar su poesía, de reorganizarla y reestructurarla a fin de darle un sentido y una orientación determinada, desde las cosas de amores de su juventud a la vocación religiosa de la vejez, lo mismo que habría hecho, si mi análisis es correcto, Juan Álvarez Gato.

En efecto, es posible que hubiera también un manuscrito de autor tras la transmisión de la obra de Ausiàs March, o al menos esto supuso su mejor estudioso, Amédée Pagès. Observó, en primer lugar, que los manuscritos más antiguos (Salamanca, Biblioteca Universitara, ms. 2244 y New York, Hispanic Society ms. B 2281, siglas $F$ y $N$ ), así como algunos de los tardíos, disponen los poemas en un orden distinto a las ediciones y los manuscritos que proceden de ellas, pues éstos adaptaron una disposición en secciones temáticas idénticas a alguno de los cancioneros que venimos estudiando; en cuanto al primer grupo, Pagès encontró una amplia serie de indicios de una ordenación interna de base cronológica ${ }^{47}$. He de destacar,

\footnotetext{
${ }^{46}$ Que algo hubo de pensar al respecto lo demuestra la anteposición, a guisa de prólogo, de una carta a Rodrigo Pimentel, conde de Benavente, de cuyo objeto nos ocuparemos más adelante. No obstante, en el estado actual de nuestros conocimientos carecemos de indicios para suponer que esta circunstancia implicó una reorganización de los textos con fines interpretativos, ideológicos o didácticos.

47 «Étude sur la chronologie des poésies d'Auzias March», Romania, 36, 1907, págs. 203-223; véase también el estudio de la transmisión textual en su Les obres d'Auzias March, 2 vols. Barcelona, Institut d'Estudis Catalans, 1912-1914, hoy en reimpresión facsimilar de València,
} 
además, que el ms. 2985 de la Biblioteca Nacional de Madrid termina con el poema "A mi acorda un dictat», donde retoma los elementos ideológicos que alimentan la producción completa del escritor (la necesidad inevitable del amor y la conciencia del pecado) y sus instrumentos habituales de pensamiento (la escolástica, imbricada en este caso intensamente con el contemptu mundi) y en el que parece haber superado aquel torcedor que atormentó intensamente toda su vida a favor de los argumentos morales y religiosos, y se cierra con una despedida de la poesía; el mismo poema ocupó originalmente la posición final en el manuscrito Esp. 479 de la Bibliothèque Nationale de Paris, donde va seguido por un «Deo gratias», aunque una mano distinta utilizó los folios en blanco que habían quedado para copiar otros poemas de March, Corella y Torrellas. Éstos dos son, por otra parte, los únicos manuscritos que nos lo han conservado ${ }^{48}$.

La crítica de los últimos años ha sido un tanto reacia a aceptar la existencia de tal cancionero ${ }^{49}$; sin embargo, han de ser tenidos en cuenta otro

Generalitat Valenciana, 1991. Recientemente han surgido dudas en torno a esta ordenación, sea sobre bases de carácter muy general, como en la tesis de doctorado de P. Ramírez i Molas, La poesia d'Auziàs March. Anàlisi textual, cronologia, elements filosòfics, Universidad de Basilea, 1970, especialmente págs. 195-212, sea al detalle de alguna de las composiciones, como en R. Archer, The Pervasive Image. The Role of Analogy in the Poetry of Ausiàs March, Amsterdam-Philadelphia, John Benjamins, 1985, págs. 6-7 y 185-186. Sin embargo, el conjunto de las indicaciones de Pagès sigue incólume.

${ }_{48}$ Véase la descripción de los dos manuscritos en los preliminares de la edición citada, págs. 14-17 y 21-28, y su índice completo en J. Massó Torrents, ob. cit., siglas $\mathrm{O}^{4}$ y $\mathrm{O}^{6}$; para los componentes ideológicos en la poesía de Ausiàs March, véanse los comentarios que acompañan cada uno de los poemas en la edición de A. Pagès y en la de P. Bohigas, Ausiàs March, Poesies, cinco volúmenes, Barcelona, Barcino, 1952-1959, así como A. Pagès, Commentaire des poésies d'Auzias March, Paris, Champion, 1925, su Auzias March et ses prédécesseurs, Paris, Champion, 1912, hoy en traducción catalana en València, Institució Alfons el Magnànim, $1990 \mathrm{y}$ los trabajos recogidos en la segunda parte de L. Badia, Tradició $i$ modernitat als segles XIV y XV. Estudis de cultura literària i lectures d'Ausiàs March, València-Barcelona, Institut Universitari de Filologia Valenciana-Publicacions de l'Abadia de Montserrat, 1993. Para las dudas en torno a la autenticidad de esta composición, basadas más en su imperfección formal que en otras razones de tipo ecdótico, véase R. Archer, "Ausiàs March en sus manuscritos: reevaluación de tres problemas fundamentales» en Hispanófila, 107, 1993, págs. 43-57, especialmente pág. 47.

${ }_{49}$ C. Romero Muñoz, «Re-imaginaciones de Ausías March», Rassegna Iberistica, 4, junio 1979, págs. 3-60. Ll. Cabré y J. Turró, «Perché alcun ordine gli habbia ad esser necessario’: la poesia d'Ausiàs March i la tradició petrarquista», en Cultura Neolatina 55, 1995, págs. 117 136 y el estado de cuestión de R. Archer, «El llegat ausiasmarquià d'Amédée Pagès», Llengua i Literatura, 7, 1996, págs. 291-315. Por último, C. Di Girolamo, en su Ausiàs March. Pagine del canzoniere, ha revisado las diversas observaciones, en su mayoría restrictivas o simplemente negadoras del principio estructurador descrito por Pagès y ha propuesto plantear el problema en otros términos: el orden cuasi cronológico de la obra de March en varios manuscritos sería resultado de una difusión capilar y progresiva, simultánea al proceso de creador, por lo que habría sedimentado en las grandes antologías en un orden semejante al cronológico. Es una postura próxima a la que en su momento había adoptado J. Ferraté en su edición, Les poesies d'Ausiàs March, segunda edición, Barcelona, Quaderns Crema, 1994, págs. xlvii-xlix. 
conjunto de factores de singular importancia. El primero es, sin duda, la existencia de un poema prologal, indudablemente posterior a gran parte de su poesía amorosa ${ }^{50}$ pero cuyo papel de apertura sólo forzando los argumentos es posible atribuir a ordenaciones posteriores a la muerte del autor ${ }^{51}$; el segundo, la presencia, como queda dicho, de una conclusión. Por fin, el índice comparativo de los testimonios más próximos a la hipotética ordenación del arquetipo, $F$ y $N$, muestra que su desorganización, iniciada ya en ambos manuscritos, se realizó por bloques, algunos de los cuales pueden rastrearse también en otros testimonios: el grupo formado por los poemas n. $^{\circ} 104-105$ aparece descolocado en $F K$, el grupo 87-95 se encuentra organizado como tal en $B K$, y en $H$ se les interpone el n. $^{\circ} 100$, pero en $D F N$ aparece $92-95$ por una parte, por otra 87-91 en $F$, los poemas n. ${ }^{\circ} 106-$ 107 forman un bloque en $K N$ y, por fin, en $F N$ se observa con claridad el grupo 77-85. Cada uno de estos grupos (77-85 ${ }^{52}$, 87-91, 92-95, 104-105, 106-107) tiene una extensión de entre $56^{\prime}$ y 72 estrofas, con la particularidad de que éstas son más en los grupos integrados por pocos poemas, menos en los que el número de poemas es mayor, como si éstos se hubieran transmitido en bloques que, originariamente, estuvieran contenidos en un mismo cuaderno ${ }^{53}$; según los datos enunciados, éstos bien pudieron ser seniones, copiados, como es frecuente en las colecciones más cuidadas, a tres estrofas por página. Ante estos datos cobra fuerza la existencia de un arquetipo del autor en el origen de la transmisión de la obra de Ausiàs March; un arquetipo, por lo que se ve, muy bien estructurado y organizado con un poema prologal y un epílogo, aunque sin romper la secuencia cronológica básica. Por último no hemos de ignorar que el esfuerzo por compilar y ordenar de forma coherente un cancionero no es sino un apartado más del esfuerzo desarrollado a lo largo de la Baja Edad Media para que

\footnotetext{
${ }^{50}$ Véase al respecto Archer, «Ausiàs March en sus manuscritos: reevaluación de tres problemas fundamentales», pág. 50 .

${ }^{51}$ Es la posición adoptada por Ll. Cabré y J. Turró, que se basan en que no todos los testimonios coinciden en la elección del mismo poema prologal y en que la organización de un cancionero según el modelo petrarquista sería coherente con el intenso petrarquismo de la corte napolitana en la segunda mitad del siglo xv. Lo cual es un buen cálculo probabilístico, pero en modo alguno una prueba.

${ }_{53}$ Nótese que el 86 es una esparsa monoestrófica que aparece sólo en $D E$.

53 Véase el esquema de la organización de cada testimonio en Archer, «Ausiàs March en sus manuscritos: reevaluación de tres problemas fundamentales», págs. 54-56. Los números de referencia son los que corresponden a la edición de Pagès, que intentó armonizar la organización de base de $F N$ con la hipótesis de una secuencia originalmente cronológica. Nótese que en los grupos con poemas numerosos, ante la necesidad de dejar espacios intermedios en blanco y rúbricas, más la rúbrica que puede anteceder a la tornada, es lógico que abarquen comparativamente más espacio que los grupos de pocos poemas, de disposición más compacta.
} 
los libros aparecieran cada vez más estructurados, más organizados y más transparentes a la inteligencia y el trabajo del lector ${ }^{54}$; y los cancioneros, de cuyo desarrollo interno nos venimos ocupando a lo largo de estas páginas, participaron plenamente en este proceso ${ }^{55}$.

También el Marqués de Santillana habría reorganizado y redimensionado su producción literaria en sus últimos años, aunque con otra intención y otros métodos. Don Íñigo, hacia 1443 o 1444, decidió enviar una edición parcial de sus obras a doña Violante de Prades, condesa de Módica y Cabrera, que nos ha llegado a través de varios cancioneros: PM1, RC1, MN6 y PN12; contendría una carta de presentación a la destinataria (como haría don Gómez unos años más tarde), la Comedieta de Ponza, compuesta a comienzos de 1436, los Proverbios, de hacia 1437, y los diecisiete primeros sonetos, género poético en que venía trabajando desde 1438; el orden es el siguiente:

\footnotetext{
${ }^{54}$ Véase la evolución del libro universitario desde el siglo XII en M. B. Parkes, «The Influence of the Concepts of Ordinatio and Compilatio on the Development of the Book», en Medieval Learning and Literature. Essays Presented to Richard William Hunt, edited by J J. G. Alexander and M. T. Gibson, Oxford, Clarendon Press, 1976, págs. 115-141, así como en A. A. Nascimento, «O livro de Teologia: génese de uma estrutura e estruturação de uma ciência», en Didaskalia, 25, 1995, págs. 235-255.

${ }^{55}$ No es mucha la investigación de carácter general sobre la organización interna de los cancioneros, si hacemos abstracción de la que se ha dedicado a su transmisión manuscrita que citaremos más adelante, la dedicada a problemas específicos de los cancioneros de autor, de la que nos iremos ocupando más despacio, y de la que atañe a los cancioneros petrarquescos y sus técnicas, sobre las que nos haremos eco también en este trabajo. Para lo que aquí nos interesa, citaré el sugerente libro de S. Huot, From Song to Book. The Poetics of Writing in Lyric and Lyrical Narrative Poetry, Ithaca-London, Cornell University Press, 1987, y más concretamente el cap. 2, dedicado a los cancioneros líricos, el artículo de J. Cerquiglini, "Quand la voix se tue: la mise en recueil de la poésie lyrique aux $\mathrm{XIV}^{\mathrm{e}}$ et $\mathrm{XV}^{\mathrm{e}}$ siècles», en La présentation du livre. Actes du colloque de Paris X-Nanterre $(4,5,6$ décembre 1985), edición a cargo de E. Baumgartner y N. Boulestreau, Paris, Paris X-Nanterre, 1987, págs. 313-327 y los trabajos de conjunto de G. Gorni, «Le forme primarie del testo poetico», en Letteratura italiana, vol. III, Torino, Einaudi, 1984, págs. 504-518, C. Bologna, "Tradizione testuale e fortuna dei classici», especialmente, págs. 445 y ss. y A. Quondam, Il naso di Laura. Lingua e poesia lirica nella tradizione del Classicismo, Ferrara, Panini, 1991, especialmente los capítulos «Il libro de poesia: tipologie e strumenti» y «Il libro de poesia tra scriptorium e tipografia», en las págs. 99-122 y 123-152 respectivamente. Otro carácter tienen los estudios que se han ido publicando en los últimos años sobre cancioneros concretos, especialmente en el ámbito provenzal y de origen italiano, entre los que destaca el libro de S. Asperti, Carlo I d'Angiò e i trovatori. Componenti "provenzali» e angioine nella tradizione manoscritta della lirica trobadorica, Ravenna, Longo, 1995; de las descripciones de algunos de ellos que interesan especialmente a esta investigación nos iremos haciendo eco a lo largo del presente trabajo. Aunque la problemática es muy diferente, ofrece sugerencias interesantes un estudio sobre manuscritos teatrales del medioevo de G. A. Runnals, "Towards a Typology of Medieval French Play Manuscripts», en The Editor and the Text, ed. de Ph. E. Bennett y G. A. Runnalls, Edinburg, Edinburg University Press, 1990, págs. 96-113.
} 


\begin{tabular}{lcccc}
\hline & MN6 & PM1 & PN12 & RC1 \\
\hline Carta & 49 & 1 & 43 & 166 \\
Comedieta & 50 & 2 & 44 & 167 \\
Sonetos & $51-67$ & & $45-61$ & \\
Proverbios & $37-38$ & & $63-64$ & \\
\hline
\end{tabular}

Como puede observarse, la única nota discordante es la aparente dislocación entre los sonetos y los Proverbios en MN6, que, con todo, es compatible con las incertidumbres de nuestras dataciones y muy explicable por la proximidad entre ambas obras; bien pudiera ser que hubiera comenzado a trabajar en los sonetos antes de lo que suponemos, pues la base de nuestra cronología estriba exclusivamente en el que conocemos como el número $\operatorname{dos}^{56}$. O bien pudiera ser que fuera PN12, y no MN6, el que conservara el orden original de ambas obras. No puede olvidarse que este cancionero reestructura ambiciosamente sus fuentes a fin de clasificar las obras por autores ${ }^{57}$ en un proyecto de gran envergadura.

Entre 1445 y 1449, el Marqués debió realizar otra edición de su obra, esta vez de mayor amplitud, destinada a don Pedro, condestable de Portugal, para la que compuso, a guisa de prólogo, el Prohemio e carta; no conservamos o no hemos sabido identificar tal cancionero, pero esta obra abriría en adelante todas las copias de los cancioneros del Marqués que parecen haber salido de su casa. Así sucedió con el que debió ordenar al final de su vida, hacia 1456, para enviar a su sobrino Gómez Manrique, y que puede ser el precioso manuscrito 2.655 de la Biblioteca Universitaria de Salamanca (SA8) ${ }^{58}$, al que antepuso, a modo de justificación del volumen, una composición de don Gómez en la que le pedía una copia de sus obras con su propia respuesta, seguidos del Prohemio e carta a título de intro-

\footnotetext{
${ }^{56}$ El estado de la cuestión en lo que respecta a la datación de la obra de Santillana puede verse en J. C. López Nieto, "Sobre la ordenación de SA8», arriba citado; para la transmisión de estas obras, véase M. P. A. M. Kerkhoff, Comedieta de Ponza, Clásicos Castellanos, 4, Madrid, Espasa-Calpe, 1987, pág. 268 y M. P. A. M Kerkhof y D. Tuin, Los sonetos al 'itálico modo' de Íñigo López de Mendoza, marqués de Santillana, Madison Hispanic Seminary of Medieval Studies, 1985, págs. 46-49. Por desgracia, carecemos de cualquier estudio sobre la transmisión de los Proverbios, una de las obras más divulgadas del siglo xv y que tanta luz podría dar para la filiación de los cancioneros. Para una visión de conjunto sobre la elaboración de los cancioneros personales del Marqués, véase la introducción de M. A Pérez Priego a las Poesias completas, vol. I, Madrid, Alhambra, 1983, págs. 3-8, así como J. L. Pérez López, El cancionero de Toledo del marqués de Santillana, Toledo, Caja de Toledo, 1989, págs. 63-98.

${ }_{57}$ De ello me he ocupado en el estudio relacionado en la nota 1.

${ }^{58}$ Existe excelente edición facsímil, Cancionero del marqués de Santillana [B. U. S., ms. 2655], Salamanca, Universidad de Salamanca-Iberduero, 1990, arriba citado.
} 
ducción general al cancionero ${ }^{59}$. En éste, nuestro autor anunciaba que había ordenado sus composiciones cronológicamente: «fize buscar e escriuir - por orden segund que las yo fize - las que en este pequeño uolumen uos enbío» ${ }^{60}$; en el cancionero de la Universidad de Salamanca, sin embargo, tal afirmación es relativa.

En efecto, el volumen comienza por los elementos descritos (petición de don Gómez, respuesta de don Íñigo, Prohemio e carta), pero luego las obras aparecen clasificadas por géneros y temas, con una organización claramente jerárquica: primero los dezires, la gran poesía que tanto enorgullecía al marqués y entre los que intercala la serie completa de los sonetos, luego, las canciones, en tercer lugar, las serranillas y, por fin, la poesía de diálogo y debate. Es en el seno de cada una de estas secciones donde la cronología, hasta donde hoy podemos colegir, ha sido respetada rigurosamente ${ }^{61}$. La organización jerárquica de cancioneros por géneros es un criterio seguido desde antiguo, desde los provenzales y franceses del siglo XIII, $\mathrm{y}$ en el arquetipo de los cancioneros galaico-portugueses tal como hoy los

59 Ambos poemas preliminares van contenidos en un bifolio de pergamino que precede al volumen, el resto del cual está compuesto de quiniones, con dos cuaterniones en su última parte, cuyos bifolios interior y exterior, como en los cancioneros de Gómez Manrique, son de pergamino, el resto, de papel (véase la descripción codicológica de P. Cátedra, en ob. cit., págs. $x x v-x x x i)$. Esto podría sugerir que el cancionero como tal era independiente de la petición de don Gómez, y que sería aprovechado para la ocasión por la anteposición de aquellos textos; ciertamente, los complementos que acompañan a algunos cancioneros (prólogos y semejantes), normalmente compuestos con posterioridad, suelen aparecer en estas mismas condiciones, así como los índices, confeccionados obligatoriamente a posteriori, pero en este caso existe además un indicio muy sólido: el folio ricamente decorado con una orla y con la divisa y armas del Marqués no es el primero, como sería de esperar, sino el quinto, donde empieza el Prohemio al Condestable. Véase muy al contrario como una bellísima orla adorna el primer folio del Cancionero de Stúñiga, reproducida en facsímil en M. y E. Alvar, Cancionero de Estúñiga. Edición paleográfica, Zaragoza, Institución Fernando el Católico, 1981, ilustración entre las páginas 40-41.

${ }^{60}$ Ed. cit., pág. 52.

61 Véase el artículo citado de J. C. López Nieto y P. Cátedra, ob. cit. págs. xxiii-xxiv de la descripción codicológica que acompaña al facsímil. En el scriptorium del Marqués se siguió trabajando y una nueva versión de su cancionero, íntimamente asociada con la anterior, es la que sirvió de fuente al ms. 3677 de la Bibioteca Nacional de Madrid (MN8), donde, si bien pudo ser respetado el orden de los textos que acabamos de resumir sucintamente, se produjeron varias inserciones en el lugar correspondiente, la más importante de las cuales afecta a seis sonetos de tema religioso, uno de los cuales fue adelantado en la serie, un tanto alterada en su ordenación interna. Véase M. A. Pérez Priego, ed. cit., págs. 6-7 y notas, y la edición crítica de M. P. A. M. Kerkhof y D. Tuin, Los sonetos 'Al italico modo' de Íñigo López de Mendoza, Marqués de Santillana, especialmente págs. 7-8. De todos modos, este arquetipo debió sufrir alteraciones más graves que van en contra de la estructura que le atribuimos si nos atenemos a su copia conocida, pues la serie de los sonetos, por ejemplo, es interrumpida después de los once primeros para intercalar una amplia sección que contiene, entre otras cosas, un grupo de intercambios con Juan de Mena, el Bias contra Fortuna con su prólogo en prosa y los Proverbios con la glosa de Pero Díaz: un total de más de cien folios. 
conocemos 62. También el Cancionero general de Hernando del Castillo se ordenaría por géneros, en una disposición sobre la que habremos de volver. Por otra parte, esta estructura tiene precedentes clarísimos, el más importante de los cuales es el cancionero personal y en parte autógrafo del duque Charles d'Orléans, cuyo resultado final revisó en persona y cuyos poemas numeró de su propia mano. Es muy posible que sus secciones estuvieran en su momento ordenadas cronológicamente, aunque hoy, tras los numerosos cambios efectuados en la estructura del cancionero, resulta un tanto difícil establecer con seguridad este principio ${ }^{63}$.

Por otra parte, el encabezamiento de un cancionero mediante un texto teórico enlaza también con un viejo hábito romance, el de usar estas compilaciones para la didáctica poética en particular y de los valores corteses en general. A lo largo del siglo XIII, los cancioneros provenzales desarrollaron un amplio comentario en prosa que introducía el conjunto de la obra de cada autor (Vidas) o cada uno de sus poemas (razós), que hoy se atribuyen principalmente a Uc de Sant Circ ${ }^{64}$; con la producción de Bertran de

62 Véase G. Gröber, «Die Liedersammlungen der Troubadours», en Romanische Studien, II, 1877, págs. 337-670, especialmente págs. 337-358. Esta investigación fue retomada por D. S. Avalle, La letteratura medievale in lingua d'oc nella sua tradizione manoscritta. Problemi di critica testuale, Torino, Einaudi, 1961, el mejor estudio de este tipo que poseemos, hoy afortunadamente reeditado con el título de I manoscritti della letteratura in lingua d'oc, con la valiosísima colaboración de Lino Leonardi a quien debemos la actualización de su contenido y bibliografía y que hemos venido citando a menudo. Para la transmisión de la poesía de los trouvères franceses y la estructura de sus cancioneros, véase R. Schwan, Die altfranzösischen Liederhandschriften, ihr Verhältniss, ihre Entstehung und ihre Bestimmung, eine litterarhistorische Untersuchung, Berlín, 1886, y para la escuela galaico-portuguesa por G. Tavani, «La tradizione manoscritta della lirica galego-portoghese», Cultura Neolatina, 27, 1967, págs. 41-94, luego con ligeras modificaciones en Poesia del Duecento nella Penisola Iberica, Roma, Edizioni dell'Ateneo, 1969, págs. 79-179 y E. Gonçalves, «Sur la lyrique galégo-portugaise. Phénoménologie de la constitution des chansonniers ordonnées par genres», en Lyrique romane médiévale: la tradition des chansonniers, págs. 447-468.

${ }^{63}$ Para el manuscrito en conjunto véase el excelente estudio de P. Champion, Le manuscrit autographe des poésies de Charles d'Orléans, Paris, 1907, en reimpresión facsimilar de Genève, Statkine Reprints, 1975; de este manuscrito me ocupé también en mi «Las grandes compilaciones y los sistemas de clasificación», cit. en la nota 1, págs. 250-254 y de un problema de orden de los folios en dos cuadernos sucesivos en otro de los trabajos que allí se citan. En el estudio de Champion se diagnostican a menudo cambios en la posición de los cuadernos a partir de transposiciones cronológicas del contenido; por otra parte, una cala en la ordenación de las ballades, tomando como base el orden que este autor adoptó en la edición de la obra de Charles d'Orléans, y que intentó reproducir la estructura inicial del manuscrito a que nos venimos refiriendo (Poésies, dos vol., col. Les classiques français du Moyen Age, 34 y 56, que cito por las ediciones de Paris, Champion, 1971 y 1966 respectivamente) da una secuencia casi totalmente cronológica (para la datación de los poemas, véanse las págs. xxiii-xxvi de la introducción al vol. I, de donde he partido para este sondeo).

64 Para las Vidas y Razos véanse las ediciones de J. Boutière y A.-H. Schutz, Biographies des troubadours. Textes provençaux des XIIt et XIVt siècles, Bibliothèque Méridionale, xxvii, Toulouse-Paris, Privat-Didier, 1950, luego reimpreso en New York-London, Johnson Reprints 
Born se realizó el curioso experimento de una suerte de «edición comentada» de origen italiano a base de amplísimas vida y razos a fin de promocionar los valores aristocráticos ${ }^{65}$; por si el objeto de este tipo de proyectos no quedara todavía bastante claro, en algún caso se produjo la adición de otros elementos para facilitar el aprendizaje, como es el caso del glosario provenzal que acompaña al cancionero $P$ 66. Probablemente era ésta también la intención de Gómez Manrique cuando hizo que sus cancioneros fueran precedidos por la carta al conde de Benavente, donde, además de justificar por su petición expresa la debilidad de haber concedido a su obra el valor suficiente para darla a la luz, hila el tópico de las armas y las letras a fin de justificar el tiempo invertido en el cultivo de la poesía, contra el parecer de «algunos haraganes [que] digan ser cosa sobrada el leer y saber alos caualleros», pues «las sçiençias no fazen perder el filo alas espadas, ni enflaqueçen los braços ni los coraçones de los caualleros» ${ }^{67}$.

Más cerca del ámbito cultural castellano, y mediante un procedimiento más próximo al del Marqués, se produjo la anteposición de un Arte de Trobar al arquetipo de los cancioneros galaico-portugueses de la Vaticana y de la Biblioteca Nacional de Lisboa, conservado en parte por el último ${ }^{68}$, y, ya a comienzos del siglo XV, Juan Alfonso de Baena ejecutó un magno proyecto divulgador de la Gaya ciencia a través del prólogo y rúbricas de su

\footnotetext{
Corporation, 1971 y, con traducción francesa de I.-M. Cluzel, en Paris, Nizet, 1973, así como la edición y prólogo, que han de consultarse con prudencia, de G. Favati, Le biografie trovadoriche, testi provenzali dei seculi XII e XIII, Biblioteca degli Studi Mediolatini e Volgari, Bolonia, 1961; entre los estudios de conjunto, el de mayor interés es el de B. Panvini, Le biografie provenzali, valore e attendibilità, Biblioteca dell'Archivum Romanicum, Firenze, 1952. Acaba de publicarse una versión al castellano de M. de Riquer, Vidas y retratos de trovadores. Textos y miniaturas del siglo XIII, Barcelona, Círculo de lectores, 1995. Para los problemas relacionados con la autoría de Uc de Sant Circ resultan imprescindibles los trabajos de S. Guida, reunidos en su mayoría en el volumen Primi approcci a Uc de Saint Circ, Messina, Rubbettino, 1996.

${ }^{65}$ V. Bertolucci Pizzorusso, «Osservazioni e proposte per la ricerca sui canzonieri individuali», en Lyrique romane médiévale: la tradition des chansonniers, págs. 273-303 y la edición de un fragmento de cancionero con este mismo contenido por R. Crespo, «Bertran de Born nei frammenti di un canzoniere provenzale», en Studi Medievali, 24, 1983, págs. 748-790.

${ }^{66}$ A. Castellani, «Le glossaire provençal-italien de la Laurentienne (ms. plut. 41, 42)», en sus Saggi di linguistica e filologia italiana e romanza (1946-1976), vol. III, Roma, 1980, págs. 90-133. Para estos aspectos véase el trabajo arriba citado de C. Bologna, especialmente pág. 472.

${ }^{67}$ Cito por la edición de Paz y Melia, vol. I, págs. 1-11, esp. pág. 2.

${ }^{68}$ Puede verse la reproducción facsimilar del volumen en Cancionero da Biblioteca $\mathrm{Na}$ cional (Colocci-Brancuti Cod. 10991), vol. I, Lisboa, Biblioteca Nacional-Imprensa NacionalCasa da Moeda, 1982, también en reproducción semidiplomática en E. Paxeco y J. P. Machado, Cancioneiro da Biblioteca Nacional (Colocci-Brancuti), facsímile e trascrição. Leitura, comentários e glossário por..., 8 vol., Lisboa, 1949-1964; hay edición crítica del Arte de trobar en J.-M. d'Heur, Recherches internes sur la lyrique amoureuse des troubadours galiciensportugais $\left(X I I^{e}-X I V^{e}\right.$ siècles), [Liège, Université de Liège], 1975, parte segunda.
} 
Cancionero ${ }^{69}$. Con estos aditamentos, una antología o la edición de un poeta adquiría una dimensión no ya sólo ejemplificadora, sino teórica y programática que aprovecharía el Marqués y, más adelante, Juan del Encina. En cuanto a la dedicatoria a la condesa de Módica que encabezaba la primera colección, por razones que convendría estudiar, fue desaprovechada, cuando bien pudo haberla integrado a título de prólogo de alguna de las obras que entonces precedía, como hizo con la de Bías contra Fortuna al entonces todavía conde de Alba o con la que antecedía los Proverbios, cuyo destinatario era el futuro Enrique IV.

Pero, como veremos más adelante, tiene mayor interés el experimento que realizó en la sección de las serranillas, y quién sabe si en otras secciones del cancionero o en todas ellas. «La sucesión de unos y otros poemas está sabiamente calculada, con equilibrada alternancia de los distintos subgéneros, formas métricas y tipos de desenlace (...) Esta organización no puede ser casual. Pudo, sí, ir surgiendo a lo largo del ciclo al configurar cada poema, impuesta por la necesidad de no repetirse (...) pero cabe también que su calculada perfección se haya conseguido a posteriori, ateniéndose en lo fundamental [para su ordenación] a la cronología, pero transgrediéndola ocasionalmente cuando así fuera oportuno para alcanzar la ponderada variedad que se pretendía» ${ }^{70}$; o que, en cualquiera de los dos casos, todos o parte de los textos hubieran sido modificados total o parcialmente para mejorar la articulación del conjunto.

Todas estas experiencias encuentran coronación adecuada en el más elaborado de los cancioneros de autor de cuatrocientos, el Cancionero que

\footnotetext{
${ }^{69}$ Véase Cancionero de Baena. Reproduced in Facsimil from the Unique Manuscript in the Bibliothèque Nationale, con prólogo de H. R. Lang, New York, Hispanic Society of America, 1926, del que existe una reimpresión de 1971 en la misma ciudad y entidad. Tenemos también la edición semidiplomática de J. M. Azáceta, Cancionero de Juan Alfonso de Baena, Madrid, CSIC, 1966, vol. I, págs. 3-15 y la más reciente de B. Dutton y J. González Cuenca, Madrid, Visor, 1993. Para la doctrina desarrollada por Baena véase H. R. Lang, «Las formas estróficas y términos métricos en el Cancionero de Baena», en Estudios eruditos in memoriam Adolfo Bonilla y San Martín, Madrid, 1927, vol. I, págs. 485-523 y M. Alvar, «La 'nueva maestría' y las rúbricas del Cancionero de Baena», en Miscellanea di studi in onore di Aurelio Roncaglia a cinquant'anni dalla sua laurea, Modena, Mucchi, 1989, vol. I, págs. 1-24. Para su objeto doctrinal y divulgador de unos valores, véase tambien C. Potvin, Illusion et pouvoir. La poétique du Cancionero de Baena, Cahiers d'Études Médiévales, 9, Montreal-Paris, Bellarmin-Vrin, 1989, págs. 31-62, que debe consultarse con prudencia por partir de un supuesto falso sobre la cronología y la intención del Cancionero (compárese con mi La canción de amor en el otoño de la Edad Media, Barcelona, PPU, 1988, págs. 43-45). Por fin, para el contexto social que propiciaba este tipo de planteamientos, véase R. Boase, The Troubadour Revival, London, Henley and Boston, Routledge \& Kegan Paul, 1978, del que hay traducción española en Madrid, Pegaso, 1981, así como las págs. 41-46 de mi estudio.

${ }^{70}$ R. Lapesa, "Las serranillas' del Marqués de Santillana», en El comentario de textos. 4. La poesía medieval, Madrid, Castalia, 1983, págs. 243-276, que cito por su reimpresión en De Berceo a Jorge Guillén, Madrid, Gredos, 1997, págs. 21-56, especialmente pág. 51.
} 
Juan del Encina publicó en Salamanca el año de $1496^{71}$, en el que aprovechó conscientemente estas experiencias, combinando a su conveniencia el repertorio de posibilidades que la tradición ponía en sus manos. Lo primero y más simple que puede decirse de este volumen es que resulta de una belleza y armonía formal, tipográfica, poco corriente, fruto de una cuidadísima composición que se esmeró particularmente en el ajuste del texto y la compaginación. El cancionero articula su estructura formal y de contenido en las siguientes secciones, de las que deberemos partir para un análisis correcto:

1. Tabla [2 ff. preliminares sin numerar, previos al primer cuaderno]

2. A los muy poderosos y cristianissimos principes don Hernando y doña ysabel. Comiença el prohemio... [f. i r.-v.]

3. Al muy esclarecido y bien aventurado principe don Juan: comiença el prohemio en vna arte de poesia castellana... [ff. ij r.-v v.]

4. A los ylustres y muy manificos señores don Fadrique de toledo y doña Ysabel pementel Duques de alva Marqueses de coria etc. Comiença el prohemio... [f. vi r.-v.]

5. Ala ylustre y muy manifica señora doña Ysabel Pementel Duquesa de Alva Marquesa de Coria etc. Comiença la natividad de nuestro salvador... [ff vij r.-xi r. Sigue una sección de poesía religiosa hasta $\mathrm{f}$. $\mathrm{xxx}$ v.]

6. A los muy esclarecidos y siempre vitoriosos principes don Hernando y doña Ysabel. Comiença el prologo enla translacion delas Bucolicas de Virgilio... [f. xxxi r.; las Bucólicas se extienden hasta el f. xlviij v.]

7. Aqui comiença el triunfo de fama trobado por Juan del enzina: dirigido y aplicado alos muy esclarecidos y siempre vitoriosos reyes don Hernando y doña Ysabel... [f. xljx r.]

8. A los ylustres y muy manificos señores don Fadrique de toledo y doña Ysabel pemetel [sic]. duques de alva marqueses de coria etc. Comiença la obra siguiente trobada por Juan del enzina la primera vez que les fue a hazer reverencia antes que le recibiessen por suyo [f. lj v. Sigue otras dos composiciones del mismo tenor y otras de circunstancias hasta el $\mathrm{f}$. lx v.]

9. Al señor don Garcia de toledo hijo primogenito delos ylustres y muy manificos señores don Fadrique de toledo y doña Ysabel pementel Duques de Alva marqueses de Coria etc. Comiença el prologo enel

${ }^{71}$ Esta parte puede verse más ampliada en la ponencia leída en Salamanca, diciembre de 1996, en el congreso conmemorativo del Cancionero de Juan del Encina. Para su estudio, he utilizado el Cancionero de Juan del Encina. Primera edición, 1496. Publicado en facsímile por la Real Academia Española, Madrid, Tipografia de la Revista de Archivos, Bibliotecas y Museos, 1928, con prólogo de E. Cotarelo, reimpreso por la propia Academia en 1989, que he colacionado con los dos ejemplares conservados, el de la propia Academia y el de la Biblioteca de El Escorial; según advertía el editor, ambos «se completan mutuamente, como hemos hecho en la presente reproducción en facsímile, que ya aparece sin omisión alguna» (pág. 3). Como veremos en algún momento, no sólo se combinaron planchas de ambos ejemplares (con especial preferencia por el de la Academia), sino que en algún momento se varió la disposición de las páginas para adaptar el resultado a los usos tipográficos modernos. 
triunfo de amor... [f. lxj r. Sigue la sección de coplas de amores hasta f. lxxxiij v.]

10. Glosas de canciones y motes por Juan del enzina [ff. lxxxiiij r.lxxxv r.]

11. Canciones hechas por Juan del enzina [ff. lxxxv v.-lxxxvj v.]

12. Romances y canciones con sus deshechas: por Juan del enzina [ff. lxxxvij r.-xc v.]

13. Villancicos hechos por Juan del enzina [ff. xcj r.-xcvj r.]

14. Vilancicos pastoriles hechos por Juan del enzina [xcvj v.-cij v.]

15. Representaciones hechas por Juan del enzina alos ilustres y muy manificos señores don Fadrique de toledo y doña Ysabel pementel: Duques de alva Marqueses de coria etc. [ff. ciij r.-cxvj r.]

Cada una de estas secciones comienza en lo alto del recto de un folio, con una rúbrica centrada en su margen superior, y los fines de cada sección tienden a coincidir con el final del verso de un folio; sólo quedan blancos en la página precedente en ff. xlviij v. y xcvj r. y sólo empiezan en lo alto del verso del folio, en lugar del recto, en lj v., lxxxv v., y xcvj v. Incluso resulta muy frecuente que poemas en el interior de una misma sección empiecen en lo alto del folio, con una rúbrica en su parte central: ff. xii r., xiv r., xiv v. xvi r., xxv r., xxxix r., xlv v., lj v., lij v., liij v., liv v., lv r., lv v., lvij v., lviij v., lx r., lxj r., lxix r., lxx r., lxxj r., lxxv r., lxxvij r., lxxviij r., lxxix r., lxxxj v., xcvij r.-xcviij v., xcix v., c r. y cij r., dejando sólo muy raramente espacios en blanco en la página anterior: xxiv v. (espacio para dos estrofas en la segunda columna), xxxvj r. (espacio para una estrofa en la seguna columna), liv v. (espacio para dos estrofas en la segunda columna), xcvj v. (espacio para dos estrofas en la segunda columna) y cij v. (espacio para cuatro estrofas en la segunda columna). Esta precisión, por supuesto, no es fruto del azar, y son muchos los lugares donde el ajuste queda en evidencia, sea apretando el texto (ff. xxij v., lxxiij v., lxxx r., lxxxv v.), sea espaciándolo (ff. xliiij r.-xlv r., xlvij v., lij r., xciij r., xiix r.), siempre a costa de las líneas en blanco entre las estrofas y entre éstas y las rúbricas que encabezan cada poema ${ }^{72}$.

La sección de villancicos (f. xcj r.-xcvj r.) es buen reflejo de esta disposición, de los problemas que hubo de vencer y de los procedimientos de trabajo que se siguieron en su organización:

\footnotetext{
${ }^{72}$ Las rúbricas relativas a una estrofa o sección, normalmente, no están separadas por ninguna línea en blanco, ni respecto a la estrofa anterior ni respecto a la siguiente. Los impresores, desde sus primeros momentos, hubieron de desarrollar la técnica de ampliar o estrechar el molde a fin de ajustar el texto a las dimensiones de los cuadernos cuando distribuían el trabajo entre varias prensas (K. Haebler, Handbuch der Inkunabelkunde, Leipzig, 1925, que cito por la traducción castellana de I. Moyano Andrés, con prólogo y riquísima anotación y actualización bibliográfica de J. Martín Abad, Madrid, Ollero y Ramos, 1995, págs. 122-123) modificando si era necesario tanto la densidad de los procedimientos abreviativos como las
} 
1. En el f. xcj r., bajo la rúbrica, centrada en el margen superior, dispone dos villancicos de la misma longitud y estructura: trístico, más cinco estrofas de siete versos más un «fin» con esta rúbrica, también de siete versos y siempre en columnas paralelas.

2. f. xcij v. Un solo villancico, con el estribillo en trístico centrado en la parte superior del folio y sus doce estrofas en dos columnas de a seis. La única disimetría es la rúbrica «fin» ante la última estrofa.

3. f. xcij r.: dos villancicos desiguales, el primero de estribillo en trístico más siete estrofas, la última de las cuales, precedida por la rúbrica «fin», encabeza la segunda columna. El segundo villancico consta de estribillo más cuatro estrofas; el espacio que separa las dos composiciones, muy amplio, y los que separan las estrofas de la segunda, más amplios que los equivalentes de la primera columna, igualan la altura de ambas, que contienen un número asimétrico de estrofas y versos.

4. f. xcij v.: dos villancicos en paralelo, de estribillo en trístico más cinco estrofas más el «fin» precedido por esta rúbrica, de siete versos cada una.

5. f. xciii r.: el mismo sistema, también con villancicos de seis estrofas, pero el estribillo es un dístico y las estrofas de sólo seis versos; con todo, ambas columnas son idénticas a las de los folios precedentes con el procedimiento muy simple de ampliar los espacios que las separan.

6. ff. xciii v.-xciiij r.: villancicos de longitud y estructura muy desigual, a dos por columna, pero de forma que cada una de ellas empieza con la rúbrica "Villancico» $\mathrm{y}$ su correspondiente estribillo y acaba con la última estrofa de la glosa precedida de la rúbrica «fin».

7. ff. xciiij v.-xcvj r.: Ante la heterogeneidad de los textos restantes, abandonó este procedimiento; deja de tomarse en consideración el factor página y ni los comienzos ni los finales de los textos coinciden con el origen de la columna o del folio; la sección termina dejando en blanco casi la mitad del espacio de la segunda columna del último folio.

\begin{abstract}
eventuales modificaciones del texto mismo (L. Hellinga, «Notes on the Order of Setting a Fifteenth-Century Book», en Quaerendo, 4, 1974, págs. 3-30) de ahí seguramente el origen de una técnica que fue utilizada artísticamente en la composición del Cancionero de 1496. Es muy probable que el origen remoto de estos procedimientos de compaginación venga de la época de los manuscritos pues los copistas, cuando se repartían los cuadernos de una obra para reproducirlos simultáneamente (un procedimiento ciertamente frecuente, véase J. Glenisson, Le livre au Moyen Age, Turnhout-Paris, Brepols, 1988, págs. 67-68), debían de cuidar estos aspectos a fin de evitar cualquier desajuste al final de las secciones encargadas a cada uno de ellos, un defecto muy frecuente en la copia por pecias. (Sobre este tema existe abundante documentación, desde el clásico libro de J. Destrez, La Pecia dans les manuscrits universitaires du XIIIe et du XIVe siècle, Paris, 1935, de donde arrancan los conocimientos actuales, hasta G. Fink-Errera, «Une institution du monde médiéval: la 'pecia'», en Revue Philosophique de Louvain, 60, 1962, págs. 184-243 y las síntesis de H. V. Shooner, «La production du livre par la pecia», en La production du livre universitaire au Moyen Age. Exemplar et Pecia, Paris, CNRS, 1988, págs. 17-38).
\end{abstract}


Sin embargo, una distribución simétrica de columnas y páginas es retomada en la sección que sigue, «Villancicos pastoriles», ff. xcvj v.-cij v., con la salvedad de este último folio, donde vuelve a quedar en blanco la mitad de la segunda columna. El conjunto, con la armonía de la compaginación, la tendencia a igualar las columnas a pesar de las desigualdades de metro y el desequilibrio que introducen las rúbricas $\mathrm{y}$, muy en particular, por la tendencia a empezar texto en lo alto del folio y terminarlo al fin, crea un ajuste de singular belleza, en cuya organización, muy probablemente, hemos de ver la mano del autor ${ }^{73}$.

${ }^{73}$ No quiero pasar por alto una sección anterior, «Canciones hechas por Juan del En-
zina», ff. lxxxv v.-lxxxvj v., que nos interesa por varios conceptos, y que contiene diecio-
cho canciones distribuidas en seis columnas, a tres por columna. A pesar de la diversa
longitud de las estrofas, de cuatro o cinco versos, la única disimetría patente se da en la
primera página pues su primera columna contiene una canción sobre quintillas y dos so-
bre cuartetas, la segunda, una sobre cuartetas, una sobre quintillas y otra sobre sextillas; a
fin de dar cabida a los tres textos, se han suprimido totalmente los blancos que habitual-
mente separan cada texto de su rúbrica y del texto siguiente. Por otra parte, en esta sec-
ción no era viable ordenar las composiciones según sus dimensiones, lo que habría facili-
tado su ajuste, pues existe, como veremos más adelante, una organización interna de ca-
rácter estilístico y retórico.

Otro tanto sucede en una de las secciones anteriores, las de coplas de circunstancias y de amores, donde los procedimientos son más variados por la desigual longitud de las composiciones, en general de mayor amplitud, pero donde el resultado es idéntico; en conjunto, y como queda dicho, existe una intensa tendencia a que cada composición, cuando sus dimensiones lo permiten, empiece en lo alto de una columna o de una página y termine con la misma. Lo más interesante, sin embargo, es el conjunto de procedimientos que ha seguido el autor para alcanzar este resultado. La primera composición, «la natividad de nuestro salvador», ocupa los ff. vij r.-xj v.: cinco folios, diez páginas a dos columnas y cinco estrofas por columna, un total de cien estrofas de nueve versos cada una. La segunda, «la fiesta de los tres reyes Magos», ocupa los ff. xij r.-xiij v., y distribuye cuatro estrofas por columna en el f. xij r. y cinco en el v. y termina con una columna de cinco y otra de tres en el f. xiij r.; las estrofas son de diez versos. Aquí empieza la «contemplacion de la muerte y passion de su precioso hijo», con dos estrofas precedidas de una larga rúbrica, que termina en el $\mathrm{v}$. del folio con cinco estrofas en cada columna; las estrofas son de nueve versos. El f. xiiij $\mathrm{r}$. se abre con la rúbrica de «Juan del enzina al crucifijo», de doce estrofas de ocho versos en dos columnas, y el f. xiiij v. empieza también con una amplia rúbrica de la «resurreccion trobada», que acaba al fin del $\mathrm{f}$. $\mathrm{xvj}$ v.: cincuenta estrofas de nueve versos distribuidas en cinco páginas a dos columnas de cinco estrofas. El resto de la sección (ff. xvij r.-xxiiij v.), con excepción de la primera página (f. xvij r.), que contiene una larguísima rúbrica y dos columnas de cuatro estrofas cada una y de la última (f. xxiiij v.), con una primera columna de cinco estrofas y una segunda de tres, está formada por catorce páginas, de las que las nueve primeras contienen dos columnas de cinco estrofas de nueve sílabas cada una; en la primera columna de la pág. xxij r. termina aquel largo texto, la «fiesta de la assuncion», con dos estrofas en su primera columna, y sigue con la «alabança y loor de la gloriosa reyna de los cielos», precedida de una rúbrica de dos líneas y tres estrofas más de cuatro versos; la columna segunda contiene seis de estas estrofas, cuyas tres últimas ocupan la primera parte de la columna xxij va; una larga rúbrica (ocho líneas) introduce el «loor de vna yglesia de nuestra señora (...) en (...) villeruela», con dos estrofas más. A partir de la segunda columna, y hasta el fin de la sección, el ajuste del texto se ha hecho a cinco estrofas de nueve versos por columna. 
En efecto, al menos en un caso existen indicios de que esta disposición pudiera haber afectado al texto: la composición que termina la sección decimosegunda, romances y canciones con sus deshechas (f. xc v.), en este caso una glosa sobre el romance «O castillo de Montanges», tiene dos estrofas menos que en el Cancionero musical de Palacio ${ }^{74}$. Aunque resulta aventurado efectuar conjeturas de esta índole, bien pudiera ser un recurso para que encajara el fin del poema, que termina la sección, con el del folio; de resultar acertada esta suposición, tendríamos la prueba cierta de haber supervisado el poeta en persona la composición tipográfica de su Cancionero, y cabría atribuirle, al menos en parte, la compaginación misma del volumen. Para confirmar esta hipótesis debería hacerse un estudio comparativo de la obra lírica de Encina en todos los cancioneros, lo cual, evidentemente, supera las posibilidades de este trabajo; una eventualidad que no tiene nada de extraño, dado que, como ya sabemos, Encina intervino en la veste gráfica de la edición, por lo general ajena a los autores ${ }^{75}$.

En la biografía literaria de Juan del Encina, hasta el año de su Cancionero, destaca intensamente el esfuerzo desplegado para entrar al servicio de los Reyes Católicos: la dedicatoria al príncipe D. Juan del Arte de poesía castellana, la doble dedicatoria de la traducción de las Bucólicas de Virgilio a los Reyes y al Príncipe... Un empeño que debió fracasar, pues en la Tragedia trobada a la dolorosa muerte del Príncipe don Juan se lamentaba de que tan luctuoso suceso hubiera tenido lugar «agora que quiso por suyo tomarme» ${ }^{76}$. En palabras de J. R. Andrews, «the Bucolicas, was a petition

74 En dicho Cancionero, el texto empieza por dos estrofas que no están en el nuestro, y sigue por las que aquí ocupan los lugares 1, 2 y 4 en este mismo orden; falta nuestra estrofa tercera. No es por tanto tan sencillo como la supresión de una parte del texto; pero de ninguna manera habría podido ajustarse la página de dar a esta glosa una estrofa más, y el resultado habría exigido recomponer el recto de este folio o invadir el recto del folio siguiente, donde empieza la sección de villancicos. Véase la edición de A. M. Rambaldo, Juan del Encina, Obras completas, vol. I-III, col. Clásicos Castellanos, 218-220, Madrid, Espasa-Calpe, S. A., 1978, n. ${ }^{\circ}$ 148, Cancionero musical de Palacio de los siglos XV y XVI en la edición de F. Asenjo Barbieri, Madrid, 1890, hoy en reimpresión facsimilar en Málaga, Centro Cultural de la Generación del 27, 1987, n. 339 y J. Romeu Figueras, La música en la corte de los Reyes Católicos, vol. IV-2, Cancionero musical de Palacio (siglos XV-XVI), vol. 3-b, Edición de los textos, Barcelona, CSIC, 1965, n. ${ }^{\circ} 356$, con sus anotaciones respectivas, siempre excelentes las de J. Romeu.

${ }^{75} \mathrm{La}$ intervención de Encina en la edición de su Cancionero en 1496 ha sido una constante por parte de los estudiosos; véase J. C. Temprano, «Introducción» a su Cancionero de las obras de Juan del Encina Salamanca 1496. Edición y concordancias, Madison, Seminary of Medieval Studies, 1983, pág. 2 y R. Gimeno, «El Cancionero de 1501 de Juan del Encina», en Actas del X Congreso de la Asociación Internacional de Hispanistas, vol. I, Barcelona, PPU, 1992, págs. 223-232.

${ }^{76}$ El texto, procedente de una impresión probablemente suelta que aparece con el Cancionero de 1516 de la Hispanic Society (y que falta, por ejemplo, en el ejemplar de esta misma edición custodiado en la Biblioteca de Catalunya) ha sido publicado íntegro por A. M. Ram- 
for entrance into royal service», $\mathrm{y}$ «there are occasional hits that the post at the Ducal palace was accepted as a second best after failure to gain royal favor ad as such it was an interim of impatient planning and speculation» ${ }^{77}$. No obstante, hay indicios sobrados de que debió relacionarse bien con la corte, pues en el Cancionero musical de Palacio que, como se sabe, es el repertorio de la Capilla Musical de los Reyes entre aproximadamente 15001520 , es «el autor mejor representado como músico y como poeta» ${ }^{78}$, y allí aparecen treinta y una composiciones a él atribuidas (aunque en algunos casos puede que sólo por la música) que ni siquiera constan en su Cancionero, la mayoría en documentación única ${ }^{79}$. Por otra parte, sus ediciones de

baldo en su edición, vol. II, n. ${ }^{\circ}$ liii, y el verso citado es el 783 . Cotarelo, en el facsímil del Cancionero de 1496, incluyó como apéndice el de otra edición que está encuadernado con el ejemplar de la Real Academia Española, allí reproducido, y que es más breve, pues está falto de 12 estrofas (no 22, como equivocadamente dice, él mismo en el prólogo, pág. 21). Para la relación de Juan del Encina con el Príncipe, véase también M. A. Pérez Priego, «Ficción teatral en la Representación ante el príncipe don Juan de Juan del Encina», en Historias y ficciones. Coloquio sobre la literatura del siglo $X V$, citado en la nota 1, págs. 337-350; véase también J. Sanz Hermida, "Cien mil esperanças allí se anegaron», en Medioevo y Literatura. Actas del $V$ Congreso de la Asociación Hispánica de Literatura Medieval, Granada, Universidad, 1995, vol. IV, págs. 304-319, donde se ocupa ampliamente de los ecos literarios de su muerte.

77 Juan del Encina. Prometheus in Search of Prestige, University of California Publications in Modern Philology, 53, Berkeley-Los Ángeles, University of California, 1959, págs. 70 y 9 respectivamente.

${ }^{78}$ En el Catálogo-indice de B. Dutton se le atribuyen 76 composiciones entre literarias y musicales; J. Romeu Figueras, a quien pertenecen estas palabras (La música en la corte de los Reyes Católicos, vol. IV-1, Cancionero musical de Palacio (siglos XV-XVI), vol. 3-A, Introducción y estudio de los textos, Barcelona, CSIC, 1965, pág. 209), le adjudica cuarenta y cuatro textos de atribución segura (por estar documentados como tales en las ediciones de su obra poética y dramática) y sesenta y una melodías; pero si sumamos éstas a los textos propios con melodía ajena (trece en total), más otro texto quizá suyo con el nombre de Fermoselle, su apellido paterno, y un estribillo también suyo con glosa anónima (Ibídem, pág. 210 y notas) nos sale la cifra de Dutton.

${ }^{79}$ Cito según Dutton, de quien doy el número de identificación de los poemas (ID), el incipit y el número que éste le asigna en MP4:

\begin{tabular}{llc}
\hline ID & Incipit & N. $^{\circ}$ \\
\hline 1953 & Pues que jamas olvidaros & 15 \\
3687 & Mortal tristura me dieron & 29 \\
3699 & Señora de hermosura & 48 \\
3700 & Triste España sin ventura & 49 \\
3718 & Una sañosa porfia & 69 \\
0811 & Pesame de vos el conde & 72 \\
3613 & No tienen vado mis males & 85 \\
3730 & Los suspiros no sosiegan & 86 \\
3738 & Si habra en este baldres & 94 \\
3739 & Vuestros amores he señora & 95 \\
3741 & Partisteisos mis amores & 97 \\
3770 & Caldero e llave madonna & 131 \\
3781 & Pues que ya nunca nos veis & 143 \\
4945 & Sabete que Bartolillo & 188 \\
4123 & No seas tan rebellado & 204 \\
3834 & Ya no espero que en mi vida & 207
\end{tabular}


1507,1509 y 1516 llevan en el frontispicio las armas regias ${ }^{80}$. Hemos de considerar también que entre 1512 y 1517 , en que desempeñó la dignidad de arcediano en la catedral de Málaga, viajó repetidamente a la Corte en representación del Cabildo; debía ser considerado, pues, un buen interlocutor ante los Reyes ${ }^{81}$. Sin embargo, si todo indica que aspiraba a entrar al servicio de los Reyes, no hay indicios para afirmar que lo consiguiera; muy al contrario, sí tenemos perfectamente documentada en su poesía y en sus obras dramáticas una larga estancia al servicio de los duques de Alba, con quienes permaneció desde 1492 hasta 1497 ó $1498^{82}$. De ahí la alternancia de Reyes, Príncipe y Duques en la estructuración de la primera parte del Cancionero.

Entre todos ellos, no cabía la menor duda respecto a su primacía. Por eso el primer cuaderno del cancionero ${ }^{83}$ se abre con el «prohemio por Juan

\begin{tabular}{lll}
\hline ID & Incipit & $\mathrm{N}^{\circ}$ \\
\hline 3837 & A tal perdida tan triste & 212 \\
3843 & Serviros y bien amaros & 220 \\
3849 & Para verme con ventura & 228 \\
3862 & El que tal señora tiene & 244 \\
1142 & Romerico tu que vienes & 270 \\
3925 & Fata la parte & 317 \\
3929 & Tan buen ganadico & 321 \\
3454 & Pelayo ten buen esfuerzo & 322 \\
3932 & Revelose mi cuidado & 326 \\
3933 & Todos los bienes del mundo & 327 \\
3954 & Partir corazon partir & 352 \\
3966 & Cucu cucu cucucu & 363 \\
3969 & Amor con fortuna & 367 \\
2997 & Circumdederunt me & 385 \\
1140 & No consuela mal de muchos & 414 \\
\hline
\end{tabular}

${ }^{80}$ Véanse las descripciones de F. J. Norton, ob. cit. n. ${ }^{\circ} 552,560$ y 691 . Uno de estos grabados fue reproducido en su Teatro completo, ed. de M. A. Pérez Priego, Madrid, Cátedra, 1991, Col. Letras Hispánicas, 339, pág. 23.

${ }^{81}$ Véase la visión de conjunto de sus andanzas en este período, que incluyen también estancias en Roma, en J. del Encina, L'opera musicale. Ed. Studio introduttivo, trascrizione e interpretazione di Clemente Terni, Messina-Firenze, Casa editrice d'Anna, 1974, págs. 20-21 y en en el prólogo de M. A. Pérez Priego al Teatro completo, págs. 15-17, que contienen resúmenes muy detallados de su biografía. En ambos casos, los datos proceden de la documentación que publicó R. Mitjana, Sobre Juan del Encina, músico y poeta (Nuevos datos para su biografia), Málaga, 1895, y «Nuevos documentos relativos a Juan del Encina», en Revista de Filologia Española, 1, 1914, págs. 275-288. Para las relaciones de Encina con los Reyes, es interesante notar que gran parte de su obra se encuentra en la sección más antigua del manuscrito, compuesta alrededor de 1500, y que la llamada por Romeu «quinta inclusión», una de las capas que se superpusieron sobre el fondo primitivo, contiene un villancico que forma parte de la Égloga de Plácida y Victoriano, lo cual nos situaría después de 1513 en que se estrenó dicha obra y, por tanto, en plena época «malagueña», cuando lo sabemos en contacto frecuente con la corte (véase J. Romeu Figueras, ob. cit. págs. 13-20, especialmente pág. 19 y loc. cit.).

82 Véase Cotarelo, ob. cit., págs. 10-12, M. A. Pérez Priego, ob. cit., págs. 12-13 y Terni, ob. cit., págs. 17-19.

${ }^{83}$ Folio a[i] r., sin otra foliación; el frontispicio y el índice sobre un bifolio aparte. En la edición facsímil, dejaron en blanco el verso de la hoja que contiene el frontispicio, que es donde empieza la tabla; cambiaron así la compaginación del original para aproximarla al uso moderno. 
del enzina en la copilacion de sus obras» dirigido «A los muy poderosos y cristianissimos principes don Hernando y doña ysabel», donde se afirma que «todas son obras hechas desde los catorze años hasta los veynte y cinco» (f. a[i] r.) para las que implora su favor; sigue el «prohemio en vna arte de poesia castellana» que esta vez se dedica «Al muy esclarecido y bien aventurado principe don Juan» ${ }^{84}$. Es después cuando aparecen los «ylustres y muy manificos señores don Fadrique de toledo y doña Ysabel pementel Duques de alva Marqueses de coria . $\tau$ » a quienes va dedicado el «prohemio por Juan del enzina en la copilacion de sus obras» (f. vj r.); y si a los Reyes les confesaba ser aquella su producción desde los catorce años, a ellos les afirma que por la protección y mercedes recibidas, así como por otras razones, «atrevime (...) a sacar en publico la probreza de mi lavor poniendola debaxo de vuestras alas y amparo» (f. vj v.). En los equilibrios mantenidos por el poeta en esta primera parte se reflejan perfectamente los que hubo de hacer para mantener contentos a sus protectores y a sus Reyes, cuyo favor deseaba, así como una habilidad para el trato de los poderosos que siempre le acompañaría ${ }^{85}$.

Empezar un cancionero mediante una carta de dedicatoria es lo más banal que se pueda imaginar; ya Juan Alfonso de Baena afirmaba haber compilado el suyo «con muy grandes afanes e trabajos, e con mucha diligençia e afection e grand deseo de agradar e complazer e alegrar e servir a la su grand realeza e muy alta señoría» de Juan II de Castilla ${ }^{86}$. Recordemos también cómo el marqués de Santillana hizo lo mismo con la carta a Violante de Prades, que encabezaba una edición de la Comedieta de Ponza, los Proverbios, y los diecisiete primeros sonetos; en otra colección destinada a su sobrino Pedro de Mendoza, señor de Almazán, incluyó una carta dedicatoria con la respuesta de éste ${ }^{87}$ y sus Proverbios van precedidos de otra dedicatoria a su destinatario, el futuro Enrique IV de Castilla, lo mismo que el Bías contra Fortuna se acompaña de una carta al conde de Alba ${ }^{88}$ o el

${ }^{84} \mathrm{~F}$. aij r. = ij r. La foliación del volumen falta a menudo y la de los cuadernos, como de costumbre, aparece sólo en su primera mitad, así que, para evitar problemas, usaré las dos según convenga.

${ }^{85}$ Aunque no siempre con tan buena fortuna. Recuérdese el episodio de su fallida relación con el marqués de Tarifa que intenté reconstruir en «Dos Liederblätter probablemente autógrafos de Juan del Encina y una posible atribución», citado en la nota 1.

${ }^{86}$ Cito por la edición de B. Dutton y J. González Cuenca, pág. 2. Véase el comentario de J. Montoya, «El primer prólogo o "dedicatoria" del Cancionero de Juan Alfonso de Baena. Su conexión con la doctrina de la Partida segunda (Tit. V, leyes 20 y21)», en Actas del III Congreso de la Asociación Hispánica de Literatura Medieval (Salamanca, 3 al 6 de octubre de 1989), Biblioteca Española del siglo xv, vol. II, Salamanca, Universidad, 1994, págs. 701-707.

87 Véase J. L. Pérez López, ob. cit., págs. 18-20.

88 Véase la edición crítica de M. Kerkhof, Íñigo López de Mendoza, marqués de Santillana, Bías contra Fortuna, Anejos del Boletín de la Real Academia Española, Anejo xxxix, Madrid, 1983. 
Cancionero general de Hernando del Castillo va precedido de la dedicatoria al conde de Oliva ${ }^{89}$. Por último, lo poco que queda de un cancionero personal de Gómez Manrique, MN29, va encabezado por una epístola a Pero González de Mendoza, hijo del Marqués de Santillana, lo mismo que, como sabemos, sus otros dos cancioneros se abren con una carta al Conde de Benavente. El precedente más cercano a esta apertura del Cancionero de 1496 es, sin lugar a dudas, el Prohemio e carta del Marqués, de cuya función nos hemos ocupado más arriba, que a su vez ha de relacionarse con el Arte de trobar que encabeza el Cancioneiro da Biblioteca Nacional.

Carecemos de información sobre una posible influencia del Prohemio e carta del Marqués sobre el Arte de poesía castellana de Encina; a su favor contaríamos con el hecho mismo de iniciar un cancionero con un tratado teórico, aunque existan, como sabemos, otros precedentes. Pero si el primero expone un cuidado resumen de la evolución poética de los pueblos románicos que va de los provenzales a los galaico-portugueses y de éstos a los castellanos, de cuyos antecedentes inmediatos afirma que «non ha mucho tienpo qualesquier dezidores e trobadorees destas artes, agora fuessen castellanos, andaluzes o de la Estremadura, todas sus obras conponían en lengua gallega o portuguesa» ${ }^{90}$ resultaría incomprensible que Juan del Encina, conociéndolo, para explicar el origen del arte afirmara: «no dudo que en Ytalia floreciesse primero que en nuestra España y de allí decendiese a nosotros (...) Y si queremos argüyr de la etimología del vocablo, si bien miramos 'trobar' vocablo ytaliano es...) ${ }^{91}$. Claro que alguien podría argumentar, quizá con razón, que si el Prohemio es un texto histórico y crítico, el Arte, muy al contrario, es descriptivo y prescriptivo; ignorar la preeminencia de los trovadores para enlazar con una Italia en la que él veía la continuación de la latinidad, tan reverenciada, podría ser también un recurso intencional de carácter programático. Por otra parte, es curioso que el Marqués no aparezca entre los autores predilectos de Juan del Encina, que él cita con delectación en diversos pasajes de sus obras, y entre los que destaca Juan de Mena. Nos quedamos, por tanto, con la duda de si fue el Prohemio e carta el inspirador del Arte de poesía castellana o, al menos, de su posición en cabeza de un cancionero.

\footnotetext{
${ }^{89}$ Véase el Cancionero general recopilado por Hernando del Castillo (Valencia, 1511). Sale nuevamente a luz reproducido en facsimile por acuerdo de la Real Academia Española, con una introducción bibliográfica, indices y apéndices por Antonio Rodríguez Moñino, Madrid, Real Academia Española, 1958, primer cuaderno.

${ }^{90}$ El prohemio e carta del marqués de Santillana, edición citada, pág. 60.

${ }^{91}$ Cito por la edición de J. C. Temprano, «El 'Arte de poesía castellana' de Juan del Encina», Boletín de la Real Academia Española, 53, 1973, págs. 323-350, cap. i, págs. 330 y 331.
} 
El Cancionero empieza de hecho en el segundo cuaderno, con una sección de poesía religiosa (f. $b[i] \mathrm{r}$. $=$ vij $\mathrm{r}$.) precedida por una rúbrica que sorprende un tanto: "Ala ylustre y muy manifica señora doña Ysabel Pementel Duquesa de Alva Marquesa de Coria etc. Comiença la natividad de nuestro salvador»; no podemos dudar de que se dedica a la Marquesa la sección completa de poesía religiosa, aunque induce a ello el hecho de que lo estén también explícitamente tres de las composiciones que siguen (ff. xij r., xiv v., xvij r., que lleva una amplia rúbrica sobre su devoción mariana) y que, por tanto, podrían parecer reiterativas; al cortesano Encina no le dolían prendas a la hora de complacer a sus señores. Esta sección está compuesta en conjunto por 27 poemas ${ }^{92}$, en su mayor parte vinculados a motivos arquetípicos de la devoción mariana. Es curioso que dos composiciones de circunstancias hayan sido dedicadas a «vna yglesia de nuestra señora nueva mente edificada en vn lugar que se dice villeruela enel obispado de salamanca» (f. [xxij] v.) y a «vna yglesia de nuestra señora nueva mente edificada en un lugar que se dice san pedro de la tarza enel obispado de çamora: llamada santa maria de la boveda» (f. xxiij v.); no he podido encontrar datos en torno a ninguna de ellas ${ }^{93}$, pero por su situación geográfica y por su invocación común a la Virgen María podemos vincularlas, aunque sea indiciariamente, al servicio de los Duques y, en particular, de la Duquesa, pues "tan "devotissima es dela gloriosa reyna de los cielos" a quien "mucho quiere y ama"» (rúbrica del f. xvij r.). En conjunto, da la impresión de que la sección entera de poesía religiosa, o al menos sus textos más representativos pueden situarse en el período del servicio a los Duques y previo a su publicación, entre 1492 y 1495.

\footnotetext{
${ }^{92}$ Como de costumbre, en el análisis del contenido del Cancionero seguiré la cuenta de B. Dutton en las dos obras citadas y, especialmente, en el Catálogo-índice pues, a pesar de las modificaciones que introduce en su edición definitiva, la inexistencia de transcripciones vuelve más fácil la visión de conjunto.

${ }_{93}$ Villeruela o formas asimilables no la he encontrado ni en P. Madoz, Diccionario geográfico-estadístico de España y sus posesiones de Ultramar, Madrid, 1845-1850, ni en la Enciclopedia Espasa ni en los catálogos documentales de las provincias de Zamora y Salamanca. En cuanto a San Pedro de la Tarza debe ser S. Pedro de Latarce, que no aparece en Madoz, pero sí en la Enciclopedia Espasa: provincia de Valladolid, partido judicial de la Mota del Marqués, diócesis de Zamora, a $22 \mathrm{~km}$ de Toro. He intentado averiguar si pertenecían a los jurisdicción de los Duques, pero no los encuentro en A. Vaca Lorenzo, y J. A. Bonilla Hernández, Catálogo de la Documentación Medieval del Archivo de la Casa de Alba, relativa a la actual provincia de Salamanca, Salamanca, 1987. Ni en M. Gómez Moreno, Catálogo monumental de España. Provincia de Salamanca, Madrid, Ministerio de Educación, 1967, ni en D. de las Heras Hernández, y C. Gutiérrez Juncid, Catálogo artístico-monumental y arqueológico de la diócesis de Zamora, Zamora, 1973, ni en el Catálogo monumental de Castilla y León. Bienes inmuebles declarados, 2 vol., coordinado por J. Rivera, Salamanca, Junta de Castilla y León-Consejería de Cultura y Turismo, 1995, he encontrado indicios de ninguno de los dos monumentos.
} 
No puede sorprendernos la presencia de la poesía religiosa en primer lugar, pues contaba con precedentes y resultaba fuertemente arraigada en las creencias del Medioevo. Hoy estamos intensamente influidos por la experiencia de Petrarca, cuyo canzoniere arranca con un poema introductorio donde están presentes, a la vez, el pasado amor («il mio primo giovenile errore») y el estado final del alma ya curada («quand'era in parte altr'uom da quel ch'i' sono»); y es al final de este proceso vital cuando el poeta se despide y cierra su cancionero con una canción a la Virgen («Vergine bella, che di sol vestita...») ${ }^{94}$. Pero si volvemos ahora la vista a la sección del Cancionero de Baena que conserva la obra de Villasandino, y que por muchos indicios parece proceder de un cancionero de autor, se abre por una cantiga mariana con su desfecha del mismo carácter, y esta misma seriación, primero las cosas de religión, después, por su orden, las de amores y otras, es la que seguirá más tarde Hernando del Castillo en su Cancionero general.

Inmediatamente después de la poesía religiosa, y en perfecta coherencia con sus planteamientos prohumanísticos, Encina publica su traducción de las Bucólicas de Virgilio ${ }^{95}$ (ff. xxxi r.-xlviij v.), dedicada «Alos muy escla-

\footnotetext{
${ }^{94}$ Cito por la edición de G. Contini y D. Ponchiroli, Canzoniere, Torino, Einaudi, 1964, del que uso la quinta edición de 1975, n. $^{\circ} 1$ y 366 . Para las fuentes, sentido e importancia de los textos prologales véase F. Rico, «Prólogos al Canzoniere», en Annali della Scuola Normale Superiore di Pisa, serie III, 18, 1988, págs. 1071-1104. Es la estructura imitada por los petrarquistas del siglo XVI, Lope de Vega por ejemplo, cuyo primer soneto de las Rimas tiene idéntica función prologal, a la vez que anticipa el desengaño ( «Versos de amor... / engendrados del alma en mis cuidados... si aquel áspid hermoso no os aceta, / dejad la tierra...) y el último propone un plan de vida que, por supuesto, Lope no iba a seguir («Venturoso rincón, amigos mudos, / libros queridos... paso en vosotros descansada vida / lejos de idolatrar en dueño ingrato»; cito por Lope de Vega, Obras poéticas, edición de J. M. Blecua, vol. I, Barcelona, Planeta, 1969).

${ }^{95}$ Para esta traducción véase M. J. Bayo, Virgilio y la pastoral española del Renacimiento, segunda edición, Madrid, Gredos, 1970, págs. 23-63, J. C. Temprano, Móviles y metas en la poesía pastoril de Juan de Encina, Publicaciones de Archivum, Oviedo, Universidad, 1977, M. Morreale, «Juan del Encina y Luis de León frente a frente como traductores de la Bucólica de Virgilio», en Edad Media y Renacimiento. Continuidades y rupturas (Actes du Colloque Moyen Age et Renaissance en Espagne, Caen, novembre, 1988), Caen, Centre de Recherches en Langues, Littératures et Civilisations du Monde Ibérique, 1991, págs. 89-118, un trabajo que forma parte de una investigación importantísima y todavía inédita cuya comunicación agradezco vivamente a la eruditísima profesora, J. K. Walsh, «Juan del Encina y el elogio curioso del rey don Fernando», en Literatura hispánica, Reyes Católicos y Descubrimiento. Actas del Congreso Internacinal sobre la Literatura Hispánica en la época de los Reyes Católicos y el Descubrimiento, Barcelona, PPU, 1989, págs. 366-375 y F. López Estrada, «Las Bucólicas de Juan del Encina y la hora de Cisneros, 1496-1516», en La hora de Cisneros, Madrid, Editorial Complutense, 1994, págs. 109-116 que señala los criterios que llevaron a Juan del Encina a posponer esta obra tras los poemas religiosos. También Ana María Rambaldo llamó la atención sobre este aspecto en El cancionero de Juan del Encina dentro de su ámbito histórico y literario, Santa Fe (Argentina), 1972, pág. 81.
} 
recidos y siempre vitoriosos principes don Hernando y doña Ysabel» (f. xxxi r.) cuya datación puede establecerse con seguridad a través de las numerosas alusiones históricas, pues el autor expresa desde el primer momento su intención de verterlas «aplicando las a los muy loables hechos de vuestro reynar segun parece en el argumento de cada vna» (f. xxxi r.) ${ }^{96}$. Probablemente, si la «aplicación» de la égloga al reinado de los Reyes Católicos no hubiera pasado del «argumento» que precede a cada una de ellas, la versión no habría sido tan criticada, pero el autor, a menudo, glosa, desarrolla o interpola el texto para que esta «aplicación» sea más ajustada, traicionando el modelo; sin embargo, estos datos resultan inestimables para el estudioso, que puede seguir su gestación casi paso a paso. Por otra parte, este procedimiento hunde sus raíces en la tradición medieval, que cristianizaba los textos clásicos, y para ello debió inspirarle la interpretación tradicional de la égloga cuarta que, si había sido tomada por una profecía del nacimiento de Cristo, él aplica al del príncipe Juan ${ }^{97}$.

El prólogo que antecede al conjunto, dedicado a los reyes, no puede evitar una alusion a la incorporación de Granada, que «ganastes con fuerça de armas», por lo que debe datarse después de enero de 1492. Sigue un segundo prólogo «Al muy esclarecido y bien aventurado principe don Juan», a quien explica que tras «dirigir y consagrar estas Bucolicas a nuestros muy poderosos reyes» desea «aplicaros parte dellas» (f. xxxij r.; lo mismo había anunciado en el prólogo a los Reyes, f. xxxi r.). En los «argumentos» que preceden al texto de cada égloga y en sus amplificaciones e interpolaciones

\footnotetext{
${ }^{96}$ Puede verse también la edición en las Obras completas a cargo de A. M. Rambaldo, vol. I, pág. 341, cuya anotación me ha sido muy útil en los pormenores que detallo a continuación.

${ }^{97}$ Los estudios sobre las corrientes proféticas en España durante la Edad Media y, en particular, durante la época de los Reyes Católicos, que subyacen a esta adaptación, han recibido en los últimos años un gran impulso. Aunque nunca puede olvidarse el monumental Visionarios, beguinos y fraticelos catalanes (siglos XIII-XV) de J. M. Pou y Martí, Vic (Barcelona), Editorial Seráfica, 1930, hoy en cuidada reimpresión, con detalladísimos índices, en Madrid, Colegio Cardenal Cisneros, 1991, y además de J. Guadalajara Medina, Las profecias del anticristo en la Edad Media, Madrid, Gredos, 1996 y R. L. Kagan, Los sueños de Lucrecia. Política y profecía en la España del siglo XVI, Madrid, Nerea, 1991, véase A. Morel-Fatio, «Souhaits de bienvenue adressés à Ferdinand le Catholique par un poète barcelonais, en 1473», Romania, 11, 1882, págs. 333-356, L. Faraudo de Saint-Germain, «Una profecía valenciana y manifestaciones del espíritu popular en Cataluña y Valencia ante los sucesos de la guerra de Granada», en Anales del Centro de Cultura Valenciana, 13, 1952, págs. 217238, J. Gimeno Casalduero, «La profecía medieval en la literatura castellana y su relación con las corrientes proféticas europeas», primero en la Nueva Revista de Filología Hispáni$c a, 20,1971$, págs. 64-89, hoy en su Estructura y diseño en la literatura medieval castellana, Madrid, Porrúa, 1975, págs. 103-142 y M. R. Scaramuzzi Vidoni, «Conquista de Granada y simbología universal en textos españoles e italianos», en Literatura hispánica, Reyes Católicos y Descubrimiento. págs. 13-18, que atañen directamente a la época que aquí nos interesa.
} 
se contienen referencias a hechos coetáneos que pueden ayudar a su datación; algunas son demasiado reculadas o excesivamente vagas para este objeto ${ }^{98}$, aunque a veces, a primera vista, aparezcan más prometedoras ${ }^{99}$. Interesa mucho más una referencia ya más reciente y concreta a la expulsión de los judíos $\left(1492^{100}\right)$ en la cuarta, a «la desastrada muerte del muy desdichado principe de Portugal» (f. xxxix r., 1491) en la quinta y al viaje de los Reyes a Aragón (agosto de 1492) en la séptima. Por su parte, la novena celebra la toma de Granada (enero de 1492), que se presenta como reciente, y la décima parece contener una alusión al conflicto del Rosellón, que acabó por la paz de Barcelona (enero de 1493). Hacia 14911492, y este último año en particular, parece el momento más apropiado para situar, por tanto, esta traducción, que debió exigirle un notable esfuerzo, un trabajo prolongado y una atención constante; estos datos nos sitúan en el período inmediatamente anterior a su entrada al servicio de los Duques. Así pues, en la.ordenación de su Cancionero, Juan del Encina sacrificó por completo la organización cronológica, que suele presidir las formas más simples de los cancioneros de autor, en beneficio de criterios socio-literarios, que imponían una determinada sucesión de los géneros poéticos. De ahí la posposición de las Bucólicas tras la poesía religiosa, que es posterior.

Estas conclusiones son reforzadas por la rúbrica que encabeza la sección siguiente, el «Triunfo de Fama», dedicado también a conmemorar las hazañas de los Reyes Católicos hasta la toma de Granada: «Despues que el mes de março y de abril se passaron siendo ya principio de mayo: Juan del enzina dio fin a recopilar y recoger todas las diez eglogas de la bucolica de Virgilio bueltas de latin en nuestra lengua castellana...» (f. xljx r.). Nos hallamos, por tanto, en la primavera de 1492, con la traducción de

98 La guerra civil y contra Portugal en la primera, el efimero reinado del infante Alfonso en la tercera, el nacimiento del príncipe don Juan (1478) y el establecimiento de la Inquisición (1480-1483) en la cuarta, nuevamente don Juan en la sexta.

${ }^{99} \mathrm{La}$ octava parece reflejar las expectativas e incertidumbres de la guerra de Granada y contiene una mención muy concreta a «las Lomas de Malaga donde fue preso el conde de Cifuentes y otros muchos cavalleros y señores»; pero se trata de un suceso muy notorio, la prisión de don Juan de Silva, conde de Cifuentes, que tuvo lugar en marzo de 1483, cuando se dirigía con otras fuerzas a la Ajarquía de Málaga, y que se prolongó hasta 1486; el conde era además Asistente de Sevilla desde 1482, por lo que le cupo un papel relevante durante toda la guerra de Granada. Véase el resumen de los hechos en F. Layna Serrano, Historia de Cifuentes, Guadalajara, Institución Provincial de Cultura «Marqués de Santillana», 1979, págs. 106-107. No parece, por tanto, que nos hallemos ante una redacción coetánea de los hechos.

100 A. M. Rambaldo, siguiendo su hipótesis de un Encina converso, cree que estas referencias serían todavía más abundantes y motivadas por el último expolio que sufrieron, su expulsión, en su El cancionero de Juan del Encina dentro de su ámbito histórico y literario, pág. 94. 
las Bucólicas lista, cuando los Reyes preparaban el viaje a Barcelona para atender, entre otros problemas, las relaciones con Francia y la devolución del Rosellón. Pero lo que ahora nos interesa es esta nueva sección, dedicada a las obras más ambiciosas; su apertura con un "Triunfo» a los Reyes se debe de nuevo a la figura de los destinatarios, pero encuentra otra motivación en la jerarquía de los géneros literarios con este subgénero surgido de los Trionfi petrarquescos ${ }^{101}$ y es por fin coherente con la cronología.

Le sigue inmediatamente (ff. lj v.-[lij r.]) «la obra (...) trobada por Juan del encina la primera vez que les fue a hazer reverencia» a los Duques, una poetización de su homenaje como servidor («Suplico con vmildad / que me reciba por suyo»... f. [lij r.]), en octavas de arte mayor (ff. [lij] v.- liij r.) que celebra su entrada al servicio de la casa ducal («en ser ya su siervo dichoso me hallo», f. [lij v.]) y una segunda composición donde presta también homenaje «Al manifico señor don Gutierre de toledo Maestre escuela de Salamanca» (ff. liij v.-[liiij] r.), totalmente paralela a la anterior. De esta forma, el poeta pudo marcar el paso del servicio regio (real o pretendido) al de los Duques; de hecho es aquí donde empieza el «cancionero profano» o, dicho de otra manera, el cancionero en sentido estricto. La sección se completa por algunas composiciones que tienen en común un asunto cortesano de tema no amoroso ${ }^{102}$; la última es «que cosa era la corte y la vida della» (ff. [lx] r.-v.), donde parece ostentar su experiencia palaciega: si primero alaba a los reyes y las ventajas que ofrece a los que en ella viven en su merced, luego aborrece los pesares que depara a los que no han alcanzado sus mieles. Es como si quisiera rematar esta sección, tan «cortesana» en el mal sentido de la palabra, con una palinodia de sus aspiraciones y la relación de sus desdichas.

Nótese que esta secuencia interesa tanto a la cronología interna de la sección como a la biografía del autor. Si a principios de mayo de 1492 ultimaba las Bucólicas y componía el Triunfo de fama, el paso al servicio de

\footnotetext{
101 Ya Andrews propuso una organización jerárquica de todo el cancionero en ob. cit., págs. 99-100.

102 «A vn amigo gran poeta que le rogo le glosasse vn villancico» (f. [liiij] v.), «a un su amigo que estava muy triste por muerte de su madre» (f. lv r.), un poema jocoso porque «le llevo una capa un tuerto y a un page otra» (f. lv[i] r. $=$ kij r.), la «almoneda trobada» (f. lv[i] v.-lvi[j] r. = kiij r.), los «Disparates trobados» (f. lvi[j] = kiij v.- lviij r.; Para el contexto literario en que debe insertarse este texto, véanse M. V. Mendes, «Encina e Vicente: disparates», en Actas do IV Congresso da Associação Hispánica de Literatura Medieval, Lisboa, Cosmos, 1993, vol. III, págs. 347-354 y A. Martínez Pérez, «Las Coplas de disparates de Juan del Encina dentro de una tipología intertextual románica», en Medioevo y Literatura. Actas del V Congreso de la Asociación Hispánica de Literatura Medieval, vol. III, págs. 261273.), el «Juycio sacado (...) delo mas cierto de toda la astrologia» (ff. lviij v.-lix v.) y «que cosa era la corte y la vida della» (ff. [lx] r.-v.).
} 
los Duques tendría lugar después de esta fecha, y el hecho puede vincularse directamente a la partida de los Reyes hacia la Corona de Aragón, donde estaban ya a principios de agosto; en este momento, Encina, ya sin esperanzas de entrar al servicio real —o quizá sea más ajustado suponer que del príncipe don Juan-, se acogió al de la casa de Alba. Por otra parte, en esta sección del cancionero, el primer poema, un Triunfo de tradición petrarquesca dedicado todavía a los Reyes, sería el más antiguo, los dos en que presta vasallaje a la familia ducal le seguirían inmediatamente y el último, la palinodia del cortesano, sería, al menos idealmente, más reciente. Nos hallaríamos, por tanto, ante una ordenación que responde a la vez a criterios jerárquicos y de preceptiva literaria, sin que podamos descartar los cronológicos.

«Al señor don Garcia de toledo hijo primogenito delos ylustres y muy manificos señores don Fadrique de toledo y doña Ysabel pementel Duques de Alva marqueses de Coria etc.» dedicó el «triunfo de amor» (f. lxj r.-lxviij v.) al que sigue una sección de coplas de amores que se prolonga hasta el f. lxxxiij v. No cabe la menor duda de que con una composición tan ambiciosa (1350 vv., construcción alegórica y de estilo elevado, tradición petrarquista...) Encina deseaba congraciarse al heredero de la casa ofreciéndole un tributo adecuado a su edad, ni de que éste era el texto más idóneo, por su concepción y pretensiones artístico-culturales ${ }^{103}$, para encabezar su cancionero amoroso.

Sigue un conjunto de secciones de menores dimensiones, dedicadas también mayoritariamente a composiciones de tema erótico, pero con el factor diferencial de su género literario: «Glosas de canciones y motes» (ff. lxxxiiij r.lxxxv r.), «Canciones», (ff. lxxxv v.-lxxxvj v.), «Romances y canciones con sus deshechas» (ff. lxxxvij r.-xc v.), «Villancicos» (ff. xcj r.-xcvj r.), «Villancicos pastoriles» (xcvj v.-cij v.) y «Representaciones hechas por Juan del enzina alos ilustres y muy manificos señores don Fadrique de toledo y doña Ysabel pementel: Duques de alva Marqueses de coria etc.» (ff. ciij r.-

${ }^{103} \mathrm{R}$. Recio ha subrayado las reminiscencias petrarquescas y ovidianas de este texto en «Algunas notas sobre el concepto de Triunfo como género: el caso del Triunfo de Amor de Juan del Encina», Hispanófila, 109, 1993, 1-10. Véase también su Petrarca en la Península Ibérica, Madrid, Universidad de Alcalá, 1996. Por su parte, C. Salinas Espinosa, en su «Sueño y alegoría en el Triunfo de amor de Juan del Encina», 'Quién hubiese tal ventura': Medieval Hispanic Studies in Honour of Alan Deyermond, London, Department of Hispanic Studies-Queen Mary and Westfield College, 1997, págs. 318-328, muestra cómo la tradición petrarquista interfiere en otra más antigua, la del sueño alegórico e Ignacio Navarrete, en su "The Order of the Poems in Encina's 1496 Cancionero», Bulletin of Hispanic Studies, 72, 1995, págs. 147-164, ha intentado demostrar que la sucesión de los textos eróticos de esta sección pretende una determinada lectura, que intenta filiar con su supuesta condición de converso a la zaga de los estudios de Andrews y de A. M. Rambaldo, quizá también demasiado pendiente de las posibles interpretaciones eróticas de una parte del vocabulario cortés. 
cxvj r.); en todos ellos destaca el mismo esfuerzo para una compaginación bella, con marcadísimo trabajo de estructuración interna, que distinguen en cada paso la elaboración de este hermosísimo volumen de cuyos pormenores nos hemos ocupado detalladamente.

Poco puede decirse de su cronología. La sección de glosas a motes y canciones contiene varios textos que son comunes al Cancionero musical de Palacio (ID4474 = 96JE-77 y MP4a-25, ID4475 = 96JE-78 y MP4a-8, ID3688 = 96JE-81 y MP4a-30); dado que aparecen en su primera parte, donde ocupan las posiciones 1,2 y 5 de un total de 11 , podría entenderse que las composiciones iniciales estaban vinculadas al entorno real y serían anteriores a su entrada al servicio de los Duques. Dejando de momento a un lado la sección de las canciones, en la que contiene canciones y romances con desfecha, el primer texto es un romance a la caída de Granada y las canciones comienzan con una serie de poemas religiosos, de los que los tres primeros son marianos, el cuarto, a los Reyes Magos (recuérdese que éstos son los temas recurrentes en la sección de poesía religiosa, que suponíamos inspirada por la duquesa de Alba) y el último, también mariano, se dice uen nombre del nuestro muy esclarecido principe don Juan» (f. 89 r.) ${ }^{104}$; siguen tres canciones amorosas y tres coplas a villancicos ajenos de los que los dos primeros aparecen también en el Cancionero musical de Palacio (ID4520 = 96JE-122 y MP4a-206 y ID4522 = 96JE-123 y MP4a-100). En la sección de los villancicos, el primero (Ya no quiero tener fe / señora sino con vos / pues que soys madre de dios») va dedicado a la Virgen, el segundo abre con un villancico a lo divino: "Quien te traxo criador / por esta montaña escura...», el tercero, ya amoroso, enlaza con éste mediante la parodia de elementos sacros, el ermitaño de amor, (ff. xcj r.-v.) tras lo que sigue un nutrido grupo de villancicos amorosos que cierran con un estribillo sobre madre e hija («Madre lo que no quereys / vos a mi no me lo deys», ff. xcvj r.) que no sé si andará aquí por la simetría con el villancico inicial, dedicado a la «madre de dios».

Sigue la sección de "Vilancicos pastoriles hechos por Juan del enzina» (xcvj v.-cij v.) y por fin, el cancionero termina con la que se dedica a su obra dramática, vinculada al servicio de los Duques y datable, por tanto, en los años inmediatamente anteriores a su publicación. Aunque la cronología de estas obras es muy apretada y discutida, en este caso sí parece que están dispuestas por orden cronológico, pues la quinta es probablemente de 1494 y en la rúbrica de la última se afirma que «Migo [sic] (...) entro y en nombre de Juan del enzina llego a presentar al duque y duquesa sus señores la copilacion de todas sus obras y alli prometio de no trobar mas salvo

\footnotetext{
104 Que puede datar perfectamente del período salmantino; recuérdese que el Príncipe era señor de esta ciudad.
} 
lo que sus señorias le mandassen» (f. cxiij r.); el autor habría cerrado su vulumen con la última de sus obras, compuesta ex profeso para la presentación de su Cancionero. De todos modos, es cierto que las de tema religioso abren la sección, por lo que cabe también plantearse la posibilidad de una reestructuración de los textos con criterios de jerarquía socio-literaria ${ }^{105}$.

Como vemos, quizá por la pobreza de elementos referenciales de las secciones líricas, resulta dificultoso, por no decir imposible, dilucidar si estos textos aparecen en orden cronológico o no; en todo caso, a juzgar por diversos indicios que hemos ido señalando, y a pesar de que a veces la cronología no sea un factor desdeñable, parece como si la organización de cada sección se hubiera basado en criterios de coherencia interna, de tipo temático o, incluso, por ecos entre los poemas que los componen. Este factor es muy visible en los folios lxxviij r.-lxxx r. (en el seno de la sección dedicada a las coplas de amores) y lxxxviii-lxxxix (romances y canciones con desfechas) así como en parte de la sección de villancicos (ff. xcv r.xcvj r.). Pero donde este procedimiento brilla con todo esplendor, y no podía ser menos, es en la sección de las canciones, concebida como un pequeño cancionero en miniatura.

En efecto, se abre con una «cancion a nuestro redentor» (f. lxxxv va, 96JE-88), sigue otra composición ascético-piadosa (96JE-89) y termina la primera columna con una «Cancion a los reyes nuestros señores» (96JE-90); de un texto a otro se repiten un pequeño número de expresiones, no siempre con el mismo sentido, que constituyen un enlace secundario, pero muy marcado. En la primera, tras recordar «el virgen concebimiento», se insiste en que «tu muerte y resurrecion (...) destruyo las falsas leyes»; en la segunda, a tenor del tema, se afirma que «Todos deven bien obrar (...) que la muerte esta muy cierta» y en la tercera se caracteriza a los Reyes como

105 Para las diversas dataciones que se han propuesto, y que no alteran los límites cronológicos que aquí nos interesan, me limito a remitir al resumen de M. A. Pérez Priego, en la introducción a su edición del Teatro completo, pág. 61, que, a su vez, sigue a J. C. Temprano, "Cronología de las ocho primeras églogas de Juan del Encina», en Archivum, 43, 1975, págs. 141-151. Resumiendo sus argumentos, todo se centra en torno a una referencia cronológica de la égloga V, que para Temprano y Pérez Priego sería de 1493, y la fecha de la octava y última, que sería de poco antes de publicarse el Cancionero, 1493 para Temprano, 1494 para Pérez Priego, con quien estoy más de acuerdo, aunque esta égloga pudo ser escrita ex profeso para la edición del cancionero. Nótese que en este momento se presenta el volumen de su poesía como ya ultimado; y quién sabe si en lugar de escenificar la entrega oficial a los Duques del volumen manuscrito preparado para la imprenta, esta rúbrica no sería el anticipo de cómo pensaba Encina ofrecer a sus protectores el Cancionero ya impreso, en cuyo caso bien pudiera ser posterior a 1494. En cualquier caso, si la égloga $\mathrm{V}$ es de 1494 y la última la más reciente, cabe imaginar una organización cronológica, aunque parece convincente el planteamiento de J. C. Temprano, que coincide con cuanto venimos exponiendo: primero irían las églogas religiosas, después, las profanas; él supone que el trastueque cronológico es total, pero la datación del resto de las obras es enteramente conjetural. 
«siervos de dios y su madre (... ) muerte delas falsas leyes». Hay por tanto en estas tres canciones un denso tejido de enlaces y ecos que configuran un microcosmos poéticos bien marcado.

Este tejido de referencias conceptuales y textuales se intensifica en los textos amorosos. El estribillo del primero (96JE-91) afirma que «Las cosas que desseamos / tarde o nunca las avemos / y las que menos queremos / mas presto las alcançamos»; la siguiente (96JE-92) empieza afirmando que "Querria no dessearos y desear no quereros», en antítesis con la anterior, pero va avanzando una serie de elementos que serán desarrollados a continuación, en un grupo de textos inseparablemente imbricados por una auténtica malla de repeticiones. Su estribillo y vuelta terminan con el verso «que me olvido de olvidaros»; de ahí que 96JE-96 empieza afirmado que «Muchas vezes he acordado / de olvidar a vos mi dios / y en acordarme de vos / hallome desacordado». 96JE-97, una canción «a vna dama el dia de los reyes», afirma en su vuelta que «Si mis'servicios quereys / no quiero mas beneficios / ni que mas galardoneys / con esto me pagareys / que recibays mis servicios», una paradoja que responde, de nuevo a 96JE-92, cuya mudanza se quejaba de que «Si os demando galardon / en pago de mis servicios / days me vos por beneficios / pena dolor y passion».

Una nueva serie parte de estos versos de 96JE-92: «daysme vos por beneficios / pena dolor y passion»; en la canción siguiente (96JE-93), tras hilar las dificultades del enamorado en la expresión de sus sentimientos, recurre a una nueva enumeración que recuerda la anterior: «mis tormentos y sospiros / mi dolor y mi cuydado». En esta misma canción, la mudanza afirma que «He callado padeciendo / con tanta fe desque os vi (...) que sin vos bivo muriendo / y $\sin$ mi que me venci», expresiones sobre las cuales basa la siguiente (96JE-94), que empieza el estribillo afirmando «Sin veros no tengo vida» y sigue en la vuelta con un «vencido de no venceros». Decíamos que 96JE-93 basaba su estribillo en los problemas del enamorado para expresar sus sentimientos: "Ya no se como encubriros / lo que siempre os he callado / pues de muy apassionado / fuerça me fuerça deziros (...)»; éste será el punto de partida de 96JE-98: «que mi mal dezir no se / a quien callar no lo puedo»; por otra parte, también en 96JE-93, la mudanza se basaba en la idea de que «He callado padeciendo / con tanta fe desque os vi / que por vos no se de $\mathrm{mi} /$ tales passiones sufriendo (...)», que será el contenido de estribillo y vuelta en 96JE-95: «Si la $f e$ y el galardon / por vn peso se pesasse / cierto soy que no faltase / gran remedio a mi passion».

A partir de $96 \mathrm{JE}-96$ se forja una nueva serie; su mudanza y vuelta afirman que «quando pienso en como os vi / pienso mas en mas amaros: / Y con este tal cuydado / cuydoso por vos (...)», un juego de palabras que volverá en el arranque de 96JE-99: «Del amor viene el cuydado / y del cuy- 
dado el penar / dela pena el sospirar / del leal enamorado»; siguen tres textos cuyo rasgo en común es el abuso de las diversas variantes de la repetitio que el propio Encina recomendaba en el cap. viii del Arte de trobar ${ }^{106}$. La última de estas composiciones, 96JE-102, empezaba asegurando que «Todos os deven servicios / servicios con aficion», a lo que responde la siguiente, 96JE-103, que «No quiero mostrar quereros / por que no tomeys favor / para mas encareceros (...); y si 96JE-102 empezaba la vuelta con un «con servicios / serviros es galardon», 96JE-103 abre la mudanza con un «desseo siempre serviros». Por otra parte, 96JE-99 introducía el tema de los suspiros, que cuajaba en formulación axiomática en los primeros versos de la vuelta: "Quel sospiro no es passion / mas descanso del tormento»; compárese con el estribillo de 96JE-104: «en sospiros de aficion / si descansa la passion / es para doblar tormento». La sección de canciones se cierra con una composición desesperanzada (96JE-105) donde la seguridad de amar correctamente viene 'sofocada por la incapacidad de conseguir la correspondencia; allí vuelven diversas expresiones anticipadas en los textos anteriores: su «tener con vos $f e$ » de la mudanza evoca el último verso de estribillo y vuelta, repetido mediante el retronx ${ }^{107}$, de $96 \mathrm{JE}-103$ : «por falta de $f e$ ni amor», «la muy crecida fe» con que empieza 96JE-98 y la «fe de fe muy llena / que segun la fe la pena / se da por vna medida» de 96JE95 que, a su vez, nos lleva a uno de los textos nucleares de toda la sección, 96JE-93: «He callado padeciendo / con tanta $f e$ desque os vi (...)». Por otro lado, he de subrayar que todas las canciones de esta última parte siguen asociadas por los recursos de adnominatio y repetitio que, como decíamos, venían intensificándose desde 96JE-99.

Es cierto que la canción de amor del cuatrocientos, y más aún en su última época, elaborada siempre sobre un vocabulario muy reducido y un repertorio de motivos cerrado y muy escaso ${ }^{108}$, constituye la base más fértil para que se produzcan este tipo de reiteraciones, aún de modo ocasional. Sin embargo, resulta difícil cerrar los ojos ante un uso tan reiterado. Por otra parte, no necesito encarecer la importancia de estos fenómenos. Desde su identificación como elementos nucleares de tipo textual en la articulación del Canzoniere petrarquesco ${ }^{109}$, la crítica no ha dejado de estudiarlos

\footnotetext{
${ }^{106}$ Para el origen y desarrollo de estos procedimientos en la poesía del siglo $\mathrm{XV}$, véase mi La canción de amor en el otoño de la Edad Media, Barcelona, PPU, 1988, en cuyo índice de conceptos aparecen relacionados.

${ }^{107}$ Para este recurso véase también mi estudio antes citado.

108 Véase mi La canción de amor en el otoño de la Edad Media, arriba citado.

109 M. Santagata, "Connessioni intertestuali nel Canzoniere di Petrarca», en Strumenti Criti$c i, 26,1975$, págs. 80-112, luego en Dal sonetto al canzoniere. Ricerche sulla preistoria e la costituzione di un genere, Padova, Liviana editrice, 1979, pp 33-76. El mismo autor ha estudiado la prehistoria de estos recursos en el tercer capítulo del libro citado, «La preistoria de ge-
} 
a fin de filiar mejor su origen y su desarrollo en la lírica romance. Hoy sabemos que estos fenómenos son muy anteriores; aparte de atisbos en el cancionero de Guiraut Riquier ${ }^{110}$, ha sido identificado en uno de los trouvères tardíos, Adam de la Halle ${ }^{111}$ y, muy en particular, en la obra de Guittone d'Arezzo 112, en los sonetos de la traducción italiana del Roman de la Rose, Il Fiore ${ }^{113}$ y en la Vita Nuova de Dante ${ }^{114}$. En conjunto, estamos todavía muy mal informados sobre la historia y el desarrollo de estas articulaciones macrotextuales en el ámbito romance, y la laguna se convierte en piélago cuando nos asomamos a la lírica hispánica, donde apenas ha habido algún trabajo en el ámbito galaico-portugués ${ }^{115}$ y no en el aspecto específico que aquí nos interesa.

Ante la ausencia de trabajos preliminares, resulta prematuro aventurar a partir de estos datos una influencia directa del Canzoniere, aunque la huella de Petrarca, si bien no sea patente en el aspecto que nos ocupa, puede observarse también en los dos Triunfos de nuestro autor. Por otro lado, ig-

nere canzoniere», y su repercusión en los cancioneros de los petrarquistas tempranos del cuatrocientos en la corte aragonesa de Nápoles en La lirica aragonese. Studi sulla poesia napoletana del secondo quattrocento, Padova, Antenore, 1979 §III.iii. Para estos problemas y la teorización que han motivado, véase además C. Segre, "Système et structures d'un 'Canzoniere'», Recherches sur les systemes signifiants (Symposium de Varsovie 1968), 1973, págs. 373-378, M. Corti, «Testo o macrotesto? I racconti di Marcovaldo di I. Calvino», en Il viaggio testuale. Le ideologie e le strutture semiotiche, 1978, págs. 186-200, S. Longhi, «Il tutto e li parti nel sistema di un canzoniere», Strumenti critici, 1979, 13, págs. 265-300 y De Robertis, "Contiguità e selezione nella costruzione del canzoniere pertrarchesco», Studi di Filologia Italiana, 43, 1985, págs. 45-66. El propio Santagata ha recopilado la investigación respecto a problemas estructurales de los cancioneros medievales en la introducción a Dal sonetto al canzoniere.

110 Véase el ya citado trabajo de V. Bertolucci, «Il canzoniere di un trovatore», Ed. cit., págs. 115-119.

${ }^{111} \mathrm{Me}$ baso en una investigación en curso de L. Formisano, a quien agradezco algunas observaciones al respecto. Véase en relación con los problemas que aquí tratamos su «Prospettive di ricerca sui canzonieri d'autore nella lirica d'oïl», en La Filologia Romanza e $i$ codici, vol. I, págs. 131-152.

112 L. Leonardi, «Guittone nel Laurenziano», arriba citado, especialmente págs. 465-469, que continúa una línea de trabajos procedentes de D. S. Avalle, Ai luoghi di delizia pieni. Saggio sulla lirica italiana del XIII secolo, Milano-Napoli, 1976, págs. 72-74, retomado en M. Santagata, ob. cit., pág. 132.

113 Santagata, ob. cit. págs. 142-143, y L. Vanossi, Dante e il «Roman de la Rose». Saggi sul «Fiore», Firenze, Olski, 1979, págs. 193-212.

114 Santagata, ob. cit., págs. 148-152.

115 G. Tavani, «Spunti narrativi e dramatici nel Canzoniere di Joam Nunes Camanês», en Annali dell Istituto Universitario Orientali. Sezione Romanza, 2, 1960, págs. 47-70, hoy en versión portuguesa en sus Ensaios portugueses, Lisboa, Imprensa Nacional-Casa da Moeda, 1988, págs. 244-257. Su análisis es válido, aunque basado exclusivamente en argumentos de tipo narrativo, y debería reforzarse mediante el estudio de las relaciones intertextuales, que también existen; no obstante, ha de señalarse que, al contrario de lo que sucede en los estudios de la tradición italiana, especialmente los posteriores a los trabajos de Santagata, implica una profunda reorganización del orden de los poemas en la tradición manuscrita. 
noro el valor exacto que deba darse a estos datos; se observará que, a diferencia de la mayor parte de sus precedentes, las relaciones intertextuales no tienden a reproducirse en canciones contiguas, y mi análisis no ha sido lo suficientemente detenido para identificar la existencia de otro tipo de relaciones que aseguren su funcionalidad ${ }^{116}$. Tampoco tenemos una información completa del funcionamiento de estos recursos en la lírica medieval, sino breves calas en puntos muy concretos que, como queda dicho, no han interesado prácticamente el ámbito de la lírica ibérica. Como en algunos de los puntos del presente trabajo no se trata ni de lejos de establecer una visión definitiva del problema, que sería pura presunción, sino de dar unos apuntes y unas vías de trabajo para el futuro; esta visión tan sumaria y parcial no puede servir sino de acicate para completar el panorama con sondeos más completos, tanto en los cancioneros de autor como en las secciones de los grandes cancioneros que puedan remontar a originales ya articulados.

En conjunto, y siguiendo una tradición bien consolidada en la Edad Media, son criterios genéricos los que marcan el devenir de las obras en el Cancionero. Un empeño de estas características estaba bien arraigado en lo más profundo de la tradición románica de los cancioneros, pero muy lejos ya y quizá fuera del alcance de Encina el Cancioneiro da Biblioteca Nacional y los cancioneros galaico-portugueses, sólo tenía un precedente inmediato en la Península, la compilación que el marqués de Santillana había dedicado a Gómez Manrique y que se conserva en su cancionero salmantino. Y que, recordémoslo, conservaba en el seno de cada sección el orden cronológico de las composiciones, algo que Encina sólo permite suponer en algunos lugares.

Un problema que se plantea inmediatamente es el de la posible relación entre el Cancionero de Juan del Encina y el Cancionero General de Hernando del Castillo. En efecto, y en una primera fase de su trabajo (los estratos más profundos exigirían un estudio a fondo que escapa a nuestras posibilidades) este editor, en la carta dedicatoria al conde de Oliva, anuncia que «ordene y distingui la presente obra por partes y distinciones e materias enel modo que se sigue. Que luego enel principio puse las cosas de deuocion y moralidad y continue a estas las cosas de amores diferenciandolas vnas y las otras por los titulos y nombres de sus auctores y $\tan$ bien puse juntas a vna parte todas las canciones los romances assi mismo a otra las inuenciones y letras de justadores en otro capitulo y tras estas las glosas de motes y luego los villancicos y despues las preguntas $\mathrm{E}$ por

${ }^{116}$ Es el caso de algunas secciones del Canzoniere, como subraya Santagata en ob. cit., pág. 73. 
quitar el fastio alos lectores que por ventura las muchas obras graues arriba leydas les causaron puse ala fin las cosas de burlas prouocantes a risa con que concluye la obra por que coja cada vno por orden lo que mas agrada asu apetito» ${ }^{117}$. La analogía en los criterios, y hasta en el orden, es evidente.

Por otra parte, en el mismo prólogo expone la prehistoria de su edición: «de veynte años aesta parte esta natural inclinacion me hizo inuestigar auer y recolegir de diuersas partes y diuersos auctores con la mas diligencia que pude todas las obras quede juan de mena aca se escriuieron o ami noticia pudieron venir delos auctores que en este genero de escreuir auctoridad tienen en nuestro tienpo» ${ }^{118}$. Dado que, hasta entonces, el Cancionero de Juan del Encina había visto ya la luz en 1496, 1501, 1505, 1507 y 1509 , teniendo en cuenta también su excelente acogida en la Corte real y los años de permanencia junto a los duques de Alba, esperaríamos ver recogida una parte considerable de su obra.' Nada más lejos de la realidad.

En primer lugar, Hernando del Castillo recogió diversas composiciones que podemos vincular a Juan del Encina sin conocer su autoría, o con atribuciones divergentes. Es el caso de los siguientes textos:

\begin{tabular}{lllll}
\hline ID & incipit & fol. & atribución & otras fuentes y atribución \\
\hline 0811 & Pesame de vos & cxxxi r. & sin atribución & MP4 f. 77 v.-78 r., MP4-72, Encina \\
6329 & Gritando va & cxxxv r. & Otro romance de don Juan Manuel & 16JE-170 \\
1101 & Asombrado el & cxxxv r. & otro r. del comendador avila & LB1, 14CG, 20MM, C. Avila, 16JE romance \\
3613 & No tienen vado & cxlvjv. & Otro villancico (tras Altamira) & EH1, 14CG; atribuido a Encina en MP4 \\
\hline
\end{tabular}

Nótese que nos hallamos ante dos casos distintos; el segundo y tercer texto no hay otro argumento para atribuirlo a Encina que su aparición en la edición de su cancionero de 1516; en los otros dos, se trata de composiciones anónimas que se atribuyen a Juan del Encina en el Cancionero musical de Palacio, donde el rubricador puede pensar en el texto, pero más a menudo tiene en cuenta la melodía. No hay, por tanto, razones sólidas a

117 Ed.cit. f. ** v. Nótese que, como es frecuente, la foliación del impreso y las signaturas alfabéticas de los cuadernos empiezan con el texto del cancionero; la dedicatoria y los índices ocupan, como suele suceder, un cuaderno previo cuyos bifolios van numerados por asteriscos en el margen inferior del recto de su primer folio.

118 Ibídem, F. * r.

119 Dutton sólo da estos testimonios, el del Cancionero general de 1514 y $20 * \mathrm{MM}$. Sin embargo, este romance gozó de amplísima difusión, aunque nadie más lo atribuyó ni directa ni indirectamente a Juan del Encina. Véase el estudio de P. Botta, «Una tomba emblematica per una morta incoronata. Letrura del romance 'Gritando va el caballero'», en Cultura Neolatina, 45, 1985, págs. 201-295. 
favor de Encina, y no puede descartarse una mejor información de Hernando el Castillo. Un caso semejante es el uso del estribillo «Montesina era la garça» para un contrafactum de Crespí de Valdaura (f. cl v.); no puede hablarse, ni cabe hacerlo, de Juan del Encina, que glosó también este villancico.

Del contenido del Cancionero de 1496, Hernando del Castillo incluye sólo dos textos: el romance «Mi libertad en sosiego» (ID 3698) y su desfecha en forma de villancico, «Si amor pone las escalas» (ID 3737, f. cxxxix v.-cxxxx r.), que atribuye a Juan del Encina; pero Hernando del Castillo sólo conserva la primera de las seis estrofas del villancico tal como figura en el Cancionero del salmantino (f. lxxxvij v.). Aparte de éstos añade otras cuatro composiciones en documentación prácticamente única, marcadas por una notable unidad temática y de destinatario de las que sólo la primera es conocida por otro testimonio, la edición de Plácida y Victoriano de Burgos, Alonso de Melgar, '¿1518-1520? (19*JP), que contiene una cuidada selección de la obra lírica de Encina. Se trata, por otra parte, de cuatro textos que han pasado prácticamente desapercibidos para sus estudiosos, a pesar de su interés intrínseco ${ }^{120}$.

En el Cancionero general, ésta es la primera de las cuatro composiciones, con la rúbrica «Aqui comença vna obra de juan del enzina llamada eco dirigida ala marquesa de cotro», íncipit «Aun que yo triste me seco» (ID 6578). Va seguida de las «Coplas que hizo juan del enzina ala prision y muerte del marques de cotro y de su hijo dirigidas ala marquesa su muger», íncipit «Dolor quen ellalma de lleno me toca» (ID 6579), del «Romançe suyo alo mismo», íncipit «Cabe la ysla del elba» (ID 6580) y un «Villancico suyo por desfecha», íncipit «No se triste consolar» (ID 6581). El texto central de este conjunto es, sin duda, el segundo, donde con lenguaje elevado canta la perseverencia del marqués, que, apresado por los turcos, sufrió martirio por no renegar. El romance nos añade muchos detalles concretos que ayudan a precisar el suceso: el título del marqués, «cotro» en las rúbricas, se convierte aquí en «Cotrón», rimando con «prisión» (vv. 2 y 4), fue preso en acción marítima por el renegado Camali junto a su hijo y juntos llevados a Turquía; el hijo murió de resultas del cautiverio, el padre, fue ejecutado por negarse a renegar y su esposa, la marquesa, Leonor Centelles, acudió a Roma a buscar dinero para pagar el rescate. Por eso el «Eco», una composición encomiástica dedicada a la Marquesa, dice: «Asso / mis entrañas en centellas (...)».

${ }^{120}$ R. O. Jones y C. R. Lee, en su Juan del Encina, Poesía lirica y cancionero musical, Clásicos Castalia, 62, Madrid, Castalia, 1975, publican dos, el eco (n..$\left.^{\circ} 105\right)$ y el romance (n. $\left.{ }^{\circ} 106\right)$; no encuentro ninguno de estos textos en la edición de A. M. Rambaldo, aunque la ausencia de índices de primeros versos y la diseminación por diversos lugares de los textos ajenos al Cancionero de 1496 dificultan enormemente la búsqueda. 
Para la datación de estos poemas tenemos algunos datos recogidos por R. O. Jones en su anotación; a partir de una alusión de Gonzalo Fernández de Oviedo, parece situar la prisión del marqués de Cotrón antes de $1499^{121}$; pero lo que más nos interesa ahora es la personalidad de su viuda, Leonor Centelles, pues el protector de Hernando del Castillo, el conde de Oliva a quien dedica su Cancionero fue ni más ni menos que Serafín Centelles ${ }^{122}$ y allí figura una invención de la marquesa de Cotrón ${ }^{123}$. Como en el caso de su relación con el duque de Tarifa, encontramos de nuevo a Encina poetizando acontecimientos destacados en la vida de los poderosos; y como entonces, volvemos a encontrar un pequeño Liederblatt que, sin duda, llegó a manos de Hernando del Castillo a través de los condes de Oliva. En conclusión: el contenido del Cancionero general de 1511 facilita información inesperada sobre la trayectoria literaria de Juan del Encina en Italia, pero

${ }^{121}$ No he podido verificar este dato; Las quinquagenas de la nobleza de España que él cita por la edición de Vicente de la Fuente, Madrid, 1880, han sido reeditadas por J. B. de Avalle-Arce con el título de Las memorias de Gonzalo Fernández de Oviedo, Chapell Hill, 1974, que tampoco he podido ver. Una alusión muy semejante a la recogida por Jones puede verse en las Batallas y quinquagenas del mismo autor, en edición también de J. B. Avalle-Arce, Salamanca, Diputación de Salamanca, 1989, pág. 199; es otro pasaje ambiguo, muy semejante a aquél, que deja también la impresión de haber sido preso el marqués de Cotrón antes de 1500. De las acciones de Camali hay una referencia de Pedro Mártir, datada en 1509 , que debo también a la competente anotación de Jones.

${ }_{122}$ De la personalidad de algunos de los Centelles se han ocupado M. de Riquer, Història de la Literatura Catalana, vol. 3, Barcelona, Ariel, 1980, págs. 374-375, A. Ferrando Francés, Els certàmens poètics valencians, València, Institució Alfons el Magnànim, 1983, (en diversos lugares; véase el detallado índice onomástico) y E. Duran en la introducción a su edición de Antonio Beccadelli el Panormita, Dels fets e dits del gran rey Alfonso. Versió catalana del segle XV de Jordi de Centelles, Barcelona, Barcino, 1990, págs. 15-29, a partir del interés que ha despertado este hijo bastardo del conde de Oliva. Para la protección de la literatura castellana por parte de esta casa, véase $\mathrm{M}$. Cahner, «Llengua i societat en el pas del segle XV al XVI. Contribució a l'estudi de la penetració del castellà als Països Catalans», en Actes del Cinquè Col.loqui Internacional de Llengua i Cultura Catalanes. Andorra, 1-6 d'octubre de 1979, a cura de J. Bruguera i J. Massot i Muntaner, Barcelona, Publicacions de l'Abadia de Montserrat, 1980, págs. 183-256, especialmente págs. 238-245. De todos modos, no he podido documentar la relación entre Leonor Centeles y Serafin Centelles, aunque es la hipótesis más verosímil para explicar la presencia de estos versos en el Cancionero general.

${ }^{123}$ No he podido encontrar noticias sobre estos marqueses de Cotrone en los genealogistas del reino de Nápoles ni en la genealogía de los condes de Oliva; no obstante, hemos de recordar que éstos hicieron carrera en Italia y su rastro se puede seguir a través de los ricos índices de los Anales de la Corona de Aragón de J. Zurita, edición de A. Canellas López, Zaragoza, Institución Fernando el Católico, 1967-1985, 9 volúmenes. Una búsqueda en los cuatro primeros volúmenes aparecidos hasta hoy de la Historia del rey don Hernando el Católico: de las empresas y ligas de Italia, Zaragoza, Institución Fernando el Católico, 1989-, ha resultado también infructuosa; espero que la aparición de los índices dé alguna luz sobre su personalidad y, en concreto, sobre su relación con los Centelles valencianos. Una invención de la Marquesa puede verse, además de en el facsímil de Cancionero general, ff. 141 v142 r., en el volumen Poesía femenina en los cancioneros, edición de M. A. Pérez Priego, Biblioteca de Escritoras, 13, Madrid, Castalia-Instituto de la Mujer, 1989, págs. 54-56. 
parece sugerir, aunque pueda parecer extraño, que Hernando del Castillo no aprovechó ninguna de las ediciones del Cancionero de Juan del Encina ${ }^{124}$. Creo que la explicación más coherente a esta aparente incongruencia está en la posibilidad de que el compilador de Valencia excluyera expresa y voluntariamente las obras ya publicadas ${ }^{125}$; lo cual vuelve muy plausible que la ordenación del cancionero se deba a su inspiración.

De cuanto venimos diciendo en las páginas precedentes se deduce que Juan del Encina no sólo abrió la perspectiva de los cancioneros de autor impresos en la Península Ibérica, sino que superó ampliamente a todos sus predecesores, de los que el más próximo fue el Marqués de Santillana, en la cuidada organización interna del suyo. Abandonó o alteró profundamente la ordenación cronológica por otra sistemática, organizó su contenido a partir de un tratado teórico, dispuso los destinatarios de la colección y de las diversas composiciones y secciones según principios estamentales y subordinó la posición de los poemas a las jerarquías en vigor, basadas en criterios socio-literarios. Cuidó extraordinariamente la disposición tipográfica, hasta el punto de que no podemos descartar que modificara algún texto para mejorarla, y tuvo en cuenta los ecos intertextuales entre las diversas composiciones de cada sección a fin de ubicarlas adecuadamente, si es que no las retocó para introducirlos, reforzarlos o intensificarlos. Por falta de trabajos preliminares no podemos afirmar hasta qué punto fueron originales muchos de estos aspectos en la tradición de los cancioneros personales o, en su caso, de los colectivos; pero no cabe duda de que, en conjunto, nos hallamos ante uno de los experimentos literarios más interesantes del cuatrocientos peninsular.

Por otra parte, no cabe duda de que nuestro nivel de información sobre todos estos aspectos es mínimo. En esta exposición no he podido hacer más que escoger algunos testimonios privilegiados que facilitaban una aproximación rápida y eficaz, y limitar mi análisis a algunos aspectos muy visibles y de aplicación inmediata en la argumentación que he desarrollado. Para

\footnotetext{
124 Nuestra extrañeza ante esta situación aumenta por el hecho de que sólo en la reimpresión de 1535 aparecen cinco composiciones más, todas ellas procedentes del Cancionero (A. Rodríguez Moñino, Suplemento al Cancionero general de Hernando del Castillo (Valencia, 1511) que contiene todas las poesías que o figuran en la primera edición y fueron añadidas desde 1514 hasta 1557, Valencia, Editorial Castalia, 1959, n. ${ }^{\circ}$ 262-266).

${ }_{125}$ Así lo intuyó B. Dutton en su «El desarrollo del Cancionero general de 1511», en Actas del Congreso Romancero-cancionero, UCLA (1984), 2 vol., Madrid, Porrúa, 1990, págs. 81-96, especialmente pág. 94; su sugerencia ha sido desarrollada y reafirmada por J. Whetnall, «El Cancionero general de 1511: textos únicos y textos omitidos», en Medioevo y Literatura. Actas del $V$ Congreso de la Asociación Hispánica de Literatura Medieval, 4 vol., Granada, Universidad, 1995, vol. 4, págs. 504-515, especialmente págs. 510-512. Nótese que en la dedicatoria afirmaba que había recogido tanto obras manuscritas como impresas, lo cual no excluye que las segundas fueran eliminadas de su antología.
} 
avanzar sustancialmente en este campo, necesitaríamos descripciones y estudios codicológicos y del contenido de todos y cada uno de los cancioneros conservados, muchos de los cuales ni siquiera he mencionado; limitándome al ámbito cuatrocentista de la Península Ibérica, citaré sólo las dos ediciones del Cancionero de Pedro Manuel de Urrea ${ }^{126}$, el interesatísimo experimento de Pedro Marcuello ${ }^{127}$, el curioso manuscrito misceláneo 18.041 de la Biblioteca Nacional de Madrid, con la obra cortesana de Fernando de la Torre, sobre quien tenemos con todo un interesante estudio ${ }^{128}$ o el Cancionero de Juan de Luzón ${ }^{129}$, por no citar sino casos bien conocidos. Pero también los fondos manuscritos franceses e italianos de este período guardan sorpresas muy notables. Necesitaríamos también un análisis detallado de los cancioneros colectivos, a fin de conocer los posibles cancioneros de autor ya perdidos, pero todavía reconstruibles. Y, sobre todo, en una investigación de este tipo, no podremos perder nunca de vista el factor comparatista: como hemos ido viendo, los recursos compositivos son los mismos en todos los ámbitos de la Romania, y sólo una perspectiva amplia y omnicomprensiva permitirá valorar factores que pueden quedar aislados, y pasar por ende desapercibidos, en el estudio de un solo ámbito literario.

De cualquier manera, caben ya unas conclusiones generales sobre cómo se constituía un cancionero de autor. El punto de partida debía ser siempre un cartapacio personal, en el que éste fuera anotando sucesivamente sus poemas en un orden que resultaba ser, en principio, cronológico; en algunos casos, cabe la posibilidad de que hubiera dividido su original en secciones ya desde el principio, a fin de clasificarlos desde alguno de los principios socioliterarios en boga ${ }^{130}$. Después, este documento es susceptible de múltiples incidencias: folios dejados primitivamente en blanco pueden ser ocupados más

${ }^{126}$ Cancionero de las obras de Pedro Manuel de Urrea, Logroño, Brocar, 1513 y (Dutton 13UC) y su segunda edición ampliada, Cancionero de todas las obras de don pedro manuel de Vrrea nueuamente añadido, Toledo, Juan de Villaquirán, 1516. Véase P. M. Jiménez de Urrea, Cancionero, ed. M. Villar, Zaragoza, Diputación, 1878, sus Églogas dramáticas y poesías desconocidas, ed. de E. Asensio, Madrid, Joyas Bibliográfias 1950, los Villancicos from the Cancionero of Pedro Manuel Jiménez de Urrea, edición de R. L. Hathaway, Exeter Hispanic Texts, Exeter, 1976, y, entre otros estudios que se le vienen dedicando, A. Egido, «Aproximación a las églogas de Pedro Manuel de Urrea», en I Curso sobre lengua y literatura en Aragón (Edad Media), Zaragoza, Institución Fernando el Católico, 1991, págs. 217-255.

127 Véase Pedro Marcuello Cancionero, edición de J. M. Blecua, Zaragoza, Institución Fernando el Católico, 1987, así como el estudio de M de C. Marín Pina, «Composición y cronología del Cancionero de Pedro Marcuello», en Archivo de Filología Aragonesa, 44-45, 1990, págs. 161-176.

128 Véase los abundantes datos reunidos en la edición de M. J. Díez Garretas, La obra literaria de Fernando de la Torre, Valladolid, Universidad, 1983.

${ }^{129}$ Zaragoza, Coci, 1508, Edición facsímil de A. Rodríguez Moñino, Madrid, J. Barbazán, 1959.

${ }^{130}$ Para esta forma de composición véase mi «Las grandes compilaciones y los sistemas de clasificación», citado en la nota 1 . 
tarde con materiales muy distintos de los que se había pensado, cabe la adición de folios, cabe el aprovechamiento de márgenes para insertar nuevos textos, quizá más tardíos, en las partes ya ocupadas (un recurso evidente en el manuscrito de Juan Álvarez Gato); y muchos de los poemas del autor, por variadísimas razones que van desde la inadvertencia hasta el repudio explícito, pueden haber quedado al margen de su cancionero personal. Sin embargo, los cancioneros conservados revelan una reelaboración a posteriori, más o menos intensa, con los objetivos más variados: desde la seriación, seguramente con alguna supresión, añadido o retoque más ciertos cambios de orden para evidenciar un inflexión ideológica, moral, estética o religiosa hasta la mera clasificación didáctica, para facilitar el acceso del lector, según géneros, temas o cualquier otra de las taxonomías en vigor. Por fin, siempre cabía retocar los textos a fin de marcar con reclamos intertextuales la sucesión o articulación de los mismos, incluso a través de estructuras a menudo muy complejas ${ }^{131}$.

Además de la ordenación cronológica, estos cancioneros suelen contener otro tipo de informaciones, generalmente en las rúbricas, que sólo el autor podía conocer; las más características son los datos sobre la datación de las composiciones, sobre su intencionalidad o sobre las circunstancias que las produjeron. Es cierto que la explicitación de estos datos constituye uno de los ejes del comentario medieval, el accessus ad auctores ${ }^{132}$, como puede comprobarse a través de los ejemplos más elaborados que nos ofrecen los cancioneros medievales, las vidas y razos provenzales o, en el caso peninsular, las rúbricas del Cancionero de Baena; pero éstas, muy a menudo, se limitan a glosar o extractar el contenido de los poemas, incurriendo las más de las veces en interpretaciones ingenuas o en errores groseros. Cuando estas rúbricas, como en el caso de Joan Berenguer de Masdovelles, incorporan información que sólo puede proceder del autor, hemos de suponer que el texto ha salido de sus manos; y si nos ha llegado a través de un cancionero particular suyo o a través de una edición amplia de sus obras contenida en una antología de mayores dimensiones, deberemos suponer que su origen está en un cancionero de autor, o en un Liederblatt si se trata de poemas sueltos.

A veces, ante la existencia de colecciones individuales, cabe dudar de si proceden de un cancionero de autor o si, por el contrario, han sido elaboradas por algún admirador suyo a posteriori, a partir de los textos conser-

131 De todos modos, ésta no es una técnica particular de los cancioneros de autor, pues puede observarse también en cancioneros colectivos y antologías de muy diversa índole.

132 Véase por ejemplo A. J. Minnis, Medieval Theory of Autorship. Scholastic Literary Attitudes in the Later Middle Ages, London, Scholar Press, 1981 y A. J. Minnis, A. B. Scott y D. Wallace, Medieval Literary Theory and Criticism c. 1100-c. 1375. The Commentary Tradition, edición revisada, Oxford, Clarendon Press, 1991. 
vados en cancioneros misceláneos. Ésta es la explicación a la existencia de una colección específica de las obras de Peire Cardenal, y la que se ha aducido para justificar las numerosas copias y ediciones de la poesía de Ausiàs March en el siglo XVI. Además de los criterios enumerados, cabe una verificación complementaria muy sencilla: ¿sería posible, a partir de los cancioneros misceláneos conservados, reconstruir sustancialmente aquella colección? En caso contrario (y creo que es el del vate valenciano) deberemos concluir que en su origen hemos de situar un cancionero personal.

El caso más extremado de la construcción de un cancionero de autor en el mundo hispánico, a la luz de nuestros conocimientos actuales, parece ser el de Juan del Encina; su paradigma universal es, sin duda, Petrarca. Pero por este camino se podía ir más lejos; desde las Vidas y Razos provenzales hasta el Voir dit de Machaut o la Vita nuova dantesca se observa una evolución, cuyos detalles no conocemos todavía, en la que la ordenación de textos enlaza con su interpretación y comentario en prosa y verso; una tradición en la que cabe incluir también el Libro de buen amor. A la postre, estas nuevas estructuras enlazarían con un tipo de novela, creada por Jean Renart a comienzos del siglo xIII, que insertaba textos líricos, pronto trasmutada en una estructura lírico-narrativa basada en la alegoría (el Dit de la panthère d'amors, por ejemplo). Pero, aunque todos estos experimentos, que caracterizan muy particularmente la vida poética del siglo XIV, no hagan sino continuar una línea creada históricamente por los cancioneros de autor, en sus métodos y sus fines divergen ya profundamente de ellos. 